\title{
Experimental and Simulation Research on the Preparation of Carbon Nano-Materials by Chemical Vapor Deposition
}

\author{
Bo Yang $1,2,3,+$, Lanxing Gao ${ }^{3,+}$, Miaoxuan Xue ${ }^{3,+}$, Haihe Wang ${ }^{3,4}$, Yanqing Hou ${ }^{1,3}$, Yingchun Luo $^{3}$, Han Xiao $^{3}$, \\ Hailiang $\mathrm{Hu}^{3}{ }^{3}$, Can Cui ${ }^{3}$, Huanjiang Wang ${ }^{3}$, Jianhui Zhang ${ }^{3}$, Yu-Feng Li ${ }^{3,5, *}$, Gang Xie ${ }^{1,3,6, *}$, Xin Tong ${ }^{3,7, *}$ (D) \\ and Yadian Xie ${ }^{3, *}$
}

check for updates

Citation: Yang, B.; Gao, L.; Xue, M.; Wang, H.; Hou, Y.; Luo, Y.; Xiao, H.; Hu, H.; Cui, C.; Wang, H.; et al. Experimental and Simulation Research on the Preparation of Carbon Nano-Materials by Chemical Vapor Deposition. Materials 2021, 14, 7356. https://doi.org/10.3390/ ma14237356

Academic Editor: Stefano Bellucci

Received: 10 October 2021

Accepted: 18 November 2021

Published: 30 November 2021

Publisher's Note: MDPI stays neutral with regard to jurisdictional claims in published maps and institutional affiliations.

Copyright: (c) 2021 by the authors Licensee MDPI, Basel, Switzerland. This article is an open access article distributed under the terms and conditions of the Creative Commons Attribution (CC BY) license (https:/ / creativecommons.org/licenses/by/ $4.0 /)$.
1 Faculty of Metallurgy and Energy Engineering, Kunming University of Science and Technology, Kunming 650093, China; gznuyangbo@163.com (B.Y.); hhouyanqing@163.com (Y.H.)

2 School of Materials and Architectural Engineering, Guizhou Normal University, Guiyang 550014, China

3 Key Laboratory of Low-Dimensional Materials and Big Data, School of Chemical Engineering, Guizhou Minzu University, Guiyang 550025, China; glxprettylife@163.com (L.G.); xuexm0418@163.com (M.X.); wanghaihe1985@163.com (H.W.); lychun36@sina.com (Y.L.); hanx@gzmu.edu.cn (H.X.); hlhu@gzmu.edu.cn (H.H.); ccals@163.com (C.C.); whj2017@gzmu.edu.cn (H.W.); gszhangjh@126.com (J.Z.)

4 Guizhou Ecological and Environment Monitoring Center, Guiyang 550014, China

5 CAS Key Laboratory for Biomedical Effects of Nanomaterials and Nanosafety, Institute of High Energy Physics, Chinese Academy of Sciences, Beijing 100049, China

6 State Key Laboratory of Common Associated Non-Ferrous Metal Resources Pressure Hydrometallurgy Technology, Kunming 650503, China

7 School of Chemistry and Materials Science, Guizhou Normal University, Guiyang 550014, China

* Correspondence: liyf@ihep.ac.cn (Y.L.); gangxie@sina.com (G.X.); tongxin@gznu.edu.cn (X.T.); xieyadian@gzmu.edu.cn (Y.X.)

+ These authors contributed equally to this work.

\begin{abstract}
Carbon nano-materials have been widely used in many fields due to their electron transport, mechanics, and gas adsorption properties. This paper introduces the structure and properties of carbon nano-materials the preparation of carbon nano-materials by chemical vapor deposition method (CVD) - which is one of the most common preparation methods-and reaction simulation. A major factor affecting the material structure is its preparation link. Different preparation methods or different conditions will have a great impact on the structure and properties of the material (mechanical properties, electrical properties, magnetism, etc.). The main influencing factors (precursor, substrate, and catalyst) of carbon nano-materials prepared by CVD are summarized. Through simulation, the reaction can be optimized and the growth mode of substances can be controlled. Currently, numerical simulations of the CVD process can be utilized in two ways: changing the CVD reactor structure and observing CVD chemical reactions. Therefore, the development and research status of computational fluid dynamics (CFD) for CVD are summarized, as is the potential of combining experimental studies and numerical simulations to achieve and optimize controllable carbon nano-materials growth.
\end{abstract}

Keywords: carbon nanotubes; carbon nano-materials; chemical vapor deposition; numerical simulations; reactor structure; chemical reactions

\section{Introduction}

Carbon is one of the most abundant elements in nature and is the basis of organic chemistry. Carbon materials can be easily produced by straightforward conversion reactions [1], and are commonly used in many fields due to their excellent electrochemical and thermodynamic properties. Over the past few decades, the discovery of carbon materials, for instance, carbon fiber, graphene, carbon nanotubes, and other carbon nano-materials, have provided unlimited possibilities for the development and utilization of carbon. 


\subsection{Carbon Fibers}

Generally, fibers with a carbon content of more than $90 \%$ are called carbon fibers [2,3]. Carbon fiber has good mechanical properties, thermal conductivity, and electrical conductivity, as well as high stability and low density. In 1879, Edison first made carbon fiber from cellulose fibers, such as bamboo, flax, or cotton yarn. However, the properties of the fibers made at that time were not good, and the process could not be industrialized. Until the early 1950s, with the development of aerospace technology, there was an increasing demand for new materials with excellent properties such as carbon fiber, and the industrial production of carbon fiber was also developed [4].

In the early 1960s, it was discovered that carbon fibers produced from polyacrylonitrile (PAN) had higher tensile and compressive strength [5]. At present, most carbon fiber is made of polyacrylonitrile. Cross-sectional images of PAN-based carbon fibers [6], are shown in Figure 1 [7]. Because carbon fiber has high strength but low density, it is often used in large devices such as airplanes and ships.
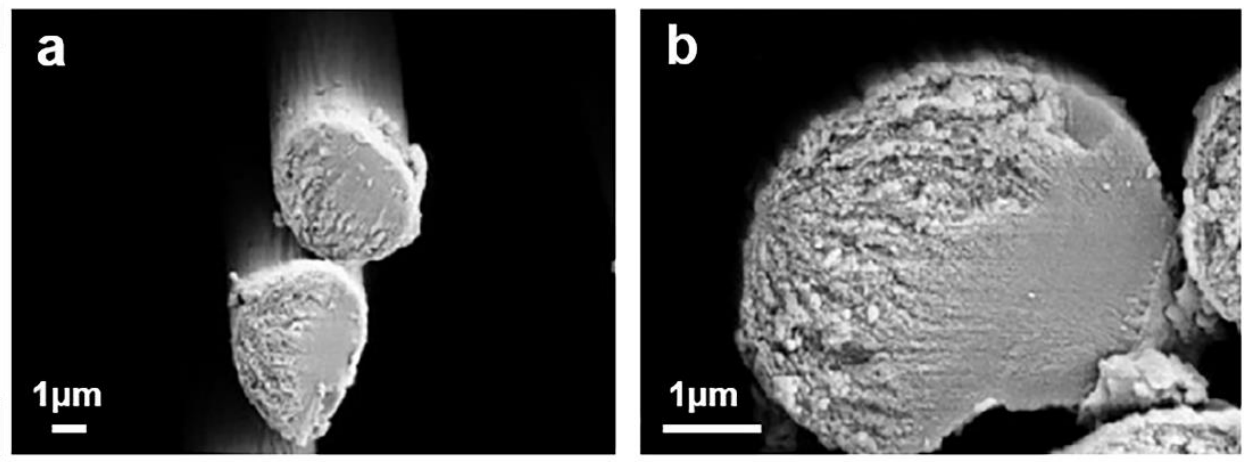

Figure 1. SEM images of carbon fibers, the magnification are (a) 10KX and (b) 30KX [7]. Copyright (C) 2021 Elsevier Ltd. and Carbon.

\subsection{Graphene}

Since Novoselov et al. separated off a single-layer graphene for the first time in 2004, its excellent performance has attracted the interest of researchers in various disciplines [8]. Single-layer graphene has the characteristics of high optical transparency, high electron mobility, high thermal conductivity, high mechanical strength, etc. [8-11]. Recently, researchers have discovered that better performance can be obtained by twisting graphene [12]. Graphene is considered as one of the most promising new materials because of its good properties and wide application [13].

Graphene is a flat two-dimensional structure formed by stacking up layers of carbon nanostructured graphite [14], as shown in Figure 2a. According to the stacking forms or the functional groups connected, graphene is divided into several different types, as show in Figure $2 \mathrm{~b}-\mathrm{f}[15-18]$.

Because of the excellent properties of graphene and its wide range of applications, it is urgent to prepare high-quality graphene with controllable structure, thickness, and size on a large scale. So far, there are many methods for preparing graphene, among which the commonly used methods are mainly mechanical exfoliation, chemical, and chemical vapor deposition (CVD). There will be an introduction later about preparing graphene by CVD. 


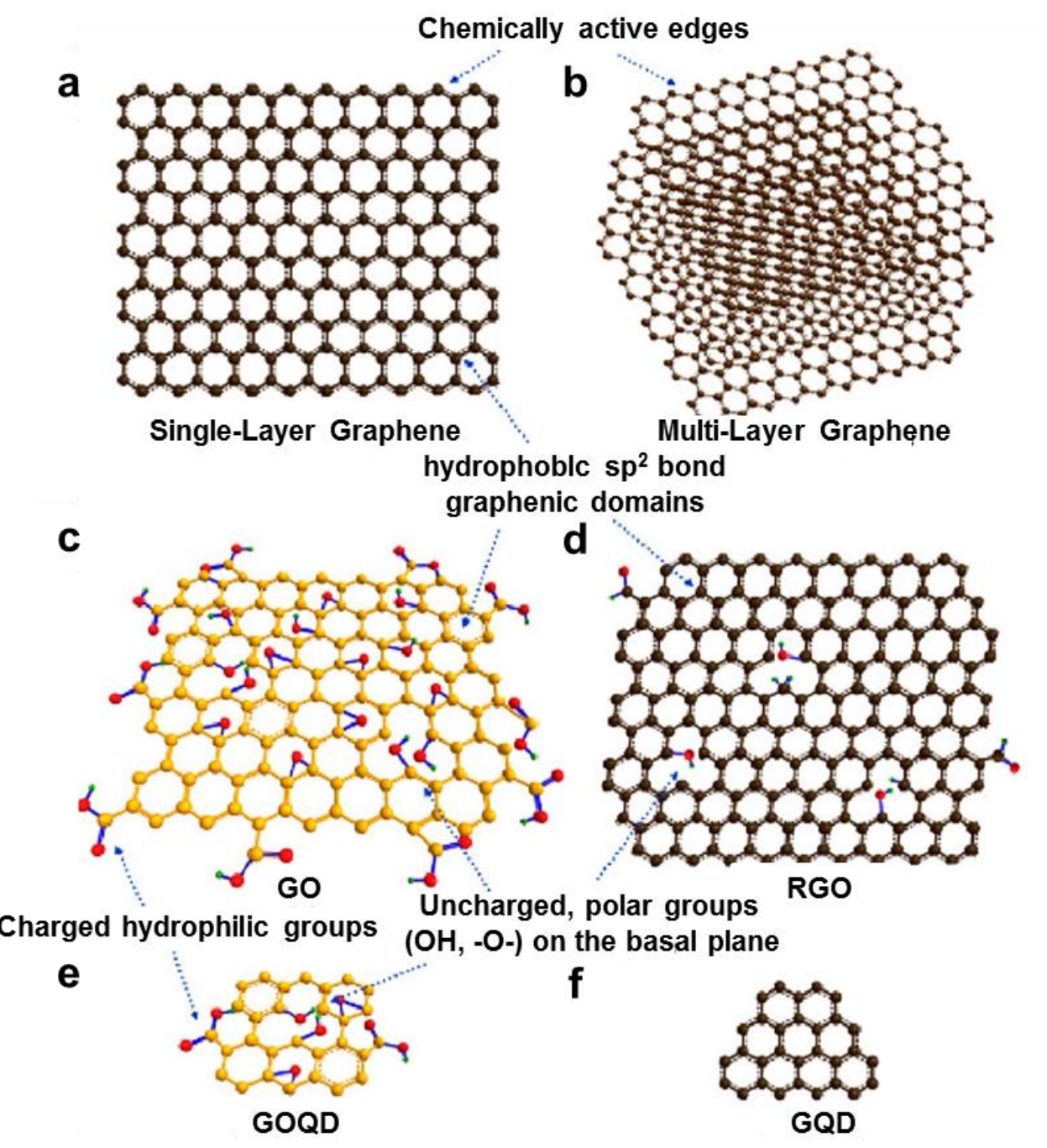

Figure 2. (a) Single-layer graphene, (b) multilayer graphene, (c) GO, (d) RGO, (e) GOQD, (f) GQD [19]. Copyright (C) 2021, The American Chemical Society.

\subsection{Graphene-like Materials}

As described above, graphene is a two-dimensional honeycomb lattice composed of single-layer carbon atoms. It is the basic component of a series of well-known carbon materials. The appearance of graphene has given researchers a lot of inspiration. They believe that two-dimensional layered materials have special and excellent properties. Therefore, there has been much research and discussion on a large number of emerging two-dimensional materials such as hexagonal boron nitride (h-BN), metal sulfides, and transition metal sulfides [20]. There are more than 40 types of transition metal dichalcogenides (TMDC), as shown in Figure 3. Like layered transition oxides [21,22], h-BN [23], and two-dimensional material topological insulators [24,25], they are all layered materials with a stacked structure.

The h-BN structure has a field-effect mobility comparable to that of graphene [26]. The $\mathrm{MoS}_{2}$ chip is a direct band gap semiconductor. These two structures, $\mathrm{h}-\mathrm{BN}$ and $\mathrm{MoS}_{2}$, are potential graphene-like materials, which have great development prospects in many fields [27-30]. 


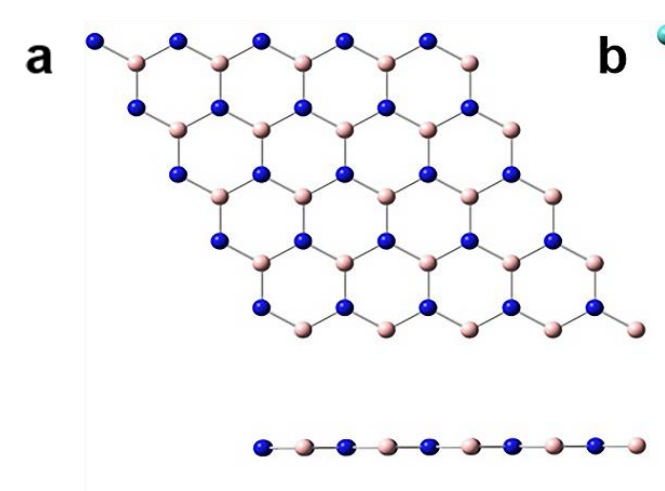

h-BN

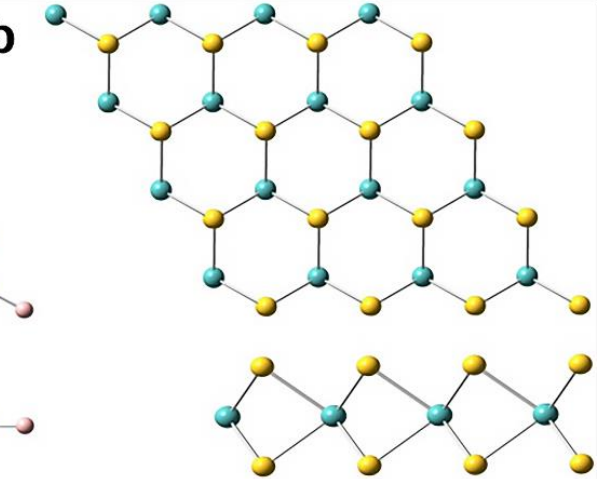

TMDC

Figure 3. (a) Structure of h-BN layers and (b) TDMC [31]. Copyright @ 2021 Elsevier B.V., Computational and Theoretical Chemistry.

As a close relative of graphene, graphene-like materials have many properties similar to graphene, such as two-dimensional geometric properties with atomic thickness, good flexibility, excellent chemical stability, high thermal conductivity, and mechanical strength. Different from graphene, graphene-like materials have the characteristics of high temperature resistance, oxidation resistance, insulation, colorlessness, and so on. When the thickness of two-dimensional layered crystal is reduced to one or several layers, the electrical and optical properties of graphene-like structures may change significantly, and show properties that graphene does not have; because of this, graphene-like two-dimensional materials have become a research hot spot.

\subsection{Carbon Nanotubes}

Carbon nanotubes are widely used due to their high aspect ratios, Young's modulus, and electrical conductivity [32,33]. Geometrically, carbon nanotubes consist of a hollow tubular structure formed by several layers of graphite sheets wound along an axis. First discovered in 1952, carbon nanotubes (CNTs) were not identified as single-walled carbon nanotubes until 1976 [34]. CNTs were later described as single-walled carbon nanotubes (SWCNTs) in 1993 [35], and multi-walled carbon nanotubes (MWCNTs) were first discovered in 1991 by Iijima, as shown in Figure 4 [36-39].

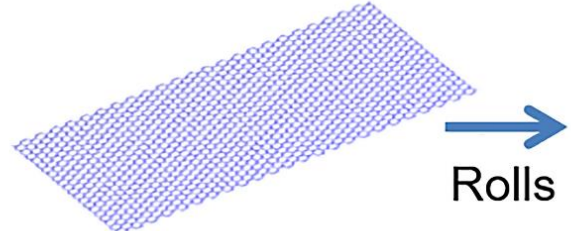

Graphene

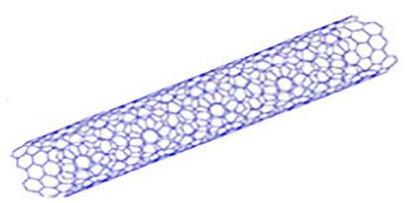

Carbon nanotube

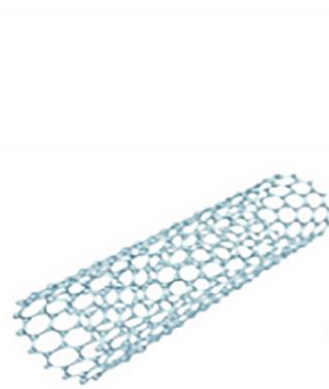

a

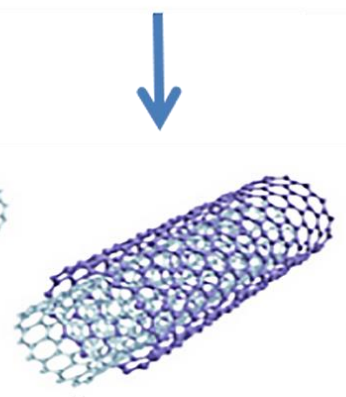

b

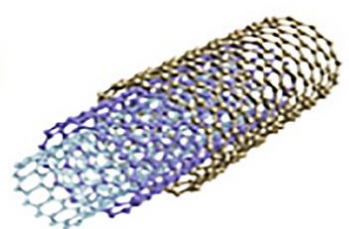

C

Figure 4. Diagram depicting carbon nanotube structures (CNTs) [38,39]: (a) single-walled CNTs; (b) double-walled CNTs; (c) multi-walled CNTs. 
Graphite sheets also have different curling angles, resulting in single-walled carbon nanotubes that can be categorized as zigzag, armchair, and chiral [40], as shown in Figure 5. New discoveries of different carbon nanostructure forms have prompted research for diverse applications. These materials have considerable application prospects in the fields of medicine [41-46], energy storage and conversion [47], sensors [48], and semiconductors [49]. Some applications have already begun to be realized. However, the specific carbon nanotube structure depends primarily on the preparation method.
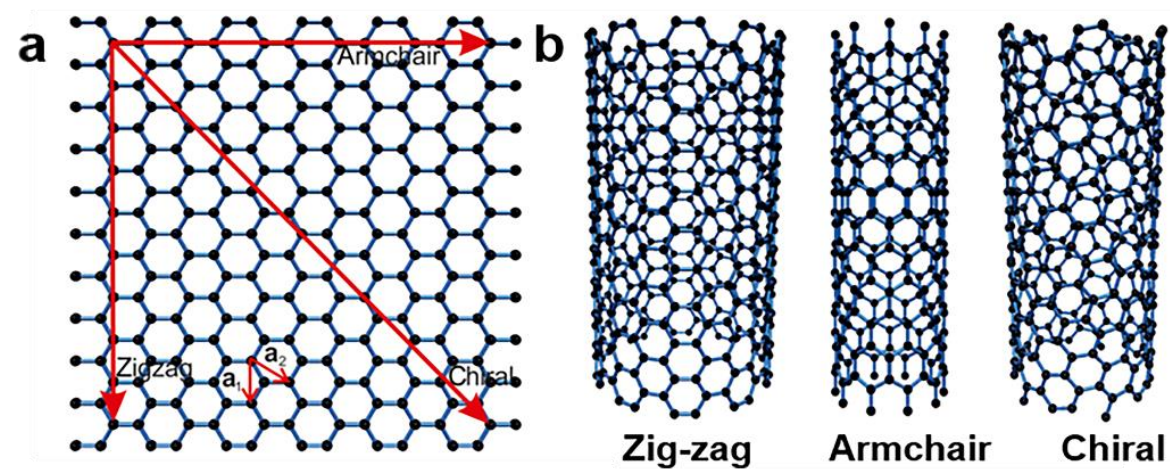

Figure 5. Different forms of single-walled carbon nanotubes (SWCNTs) [35]. (a) The chiral vector C determines the tube diameter; (b) the three structural forms of SWCNT structures.

Typical carbon nanotube preparation methodologies include arc discharging, laser ablation, chemical vapor deposition (CVD), and flame methods. Among these methodologies, CVD is a controllable and scalable method that can produce high-quality, large-area, two-dimensional materials at a reasonable cost. The basic principle of CVD is the decomposition reaction that occurs when the carbon-containing gas flows through the surface of a catalyst, generating carbon nanotubes on the surface of the catalyst [50]. In terms of product cleanliness and industrial scale, CVD is the most suitable method for producing carbon nanotubes. This method can also control the number of layers of our target product through certain means to maximize the practical value of the material.

The CVD process has the benefits of low cost, simple operation, and high product purity. However, many factors influence the CVD process, and the morphology of the final product is not easy to control. Because CNTs with different morphologies have different properties and applications, an in-depth study of nanostructured CNTs growth control factors is needed. Therefore, some important parameters that affect the quality of carbon nanotubes during the preparation process are also discussed later in this article. Examples include the carbon source and catalyst used in the preparation process and the control of some parameters (temperature, time, air flow rate, etc.) in the process [51].

Several studies have noted that the variable and difficult-to-control experimental conditions primarily affect the surface factors of CNTs, and local atmospheric changes in the reactor are the key to controlling the morphology of CNTs. Recently, in order to control the preparation of CNT materials, some researchers have started using computational fluid dynamics (CFD) software to simulate the gas concentration, temperature, and pressure distribution in the reactor, as well as the morphology of the nano- and micro-structured CNTs.

This paper introduces how the morphology of the structure affects the properties of the materials and discusses in detail the preparation and simulation of carbon fiber, graphene, carbon nanotubes, and carbon nano-materials. The influence of chemical vapor deposition on the preparation of carbon nanotubes is primarily discussed. Additionally, the factors affecting the preparation of carbon nanotubes by chemical vapor deposition and the key results of carbon nanotube CFD simulation are discussed in detail. 


\section{Structure and Properties}

\subsection{Carbon Fibers}

Commercial carbon fibers are typically $5-10 \mu \mathrm{m}$ in diameter. Compared with glass fiber, because of its higher production cost, it does not get a large market. It was not until the end of the 20th century that carbon fiber began to be used in a variety of applications, with a downward trend in its price [5]. In recent years, more than $90 \%$ of carbon fibers are PAN fibers, which play an important role in making commercial carbon fibers, and the rest of carbon fibers are made from pitch.

In 1993, Kumar et al. found through experiments that the axial compressive strength of carbon fiber varies with the tensile modulus of the fiber and the precursor material required for preparation [52]. By comparing the structure and morphology of carbon fibers made from asphalt and polyacrylonitrile, they found that the width of the graphite sheet, the size of the microcrystals perpendicular to the fibers, and the anisotropy of the crystals play a significant role in explaining the difference in the compressive strength of carbon fibers. Huang et al. proved that carbon fibers made from pitch and polyacrylonitrile do have different microstructures [53]. Through research, it was found that the fiber structure made from pitch is relatively more uniform, whereas the fiber made from polyacrylonitrile has obvious differences but also has better arranged crystallites. In this way, people have a deeper understanding of the relationship between the structure of carbon fiber and mechanical properties.

The microstructure of carbon fiber is closely related to the precursor and processing conditions. Different models describing microstructure have been proposed. Perret et al. reported that voids have a preferred orientation in the fiber axis [4]. Watt and Johnson reported a branched microfiber structure in which most of the fibers are arranged along the fiber axis, and the width of these fibers is approximately $10 \mathrm{~nm}$. Fourdeux et al. proposed a similar rayon carbon fiber fold band model. The average width of the banded monatomic layer is $6 \mathrm{~nm}$ and the length is approximately hundreds of nanometers. Needlelike micropores with a diameter of approximately 1-2 $\mathrm{nm}$ are enclosed in the plane of the stacked layer. The cross-section of traditional carbon fiber is circular. Modifying its circular surface profile to a more complex geometry requires controlling carbon etching or photolithography pattern carbon growth along the length of the fiber. Hunt et al. combined the spinning of bicomponent fibers and the carbonization of the required components with comparable properties to produce unidirectional, patterned, and continuous carbon fibers [54].

\subsection{Graphene}

Graphene has a two-dimensional cellular lattice structure composed of a layer of carbon atoms, which looks like the plane of a hexagonal grid [55] (Figure 6a,b). Each carbon atom hybridized with adjacent carbon atoms to form a regular hexagon, and each hexagonal unit is similar to a benzene ring. Each carbon atom contributes a bond free electron, and the graphene monolayer is only $0.335 \mathrm{~nm}$. When being bent and deformed by an external force, the carbon atoms do not need to be rearranged to adapt to the external force, thus ensuring structural stability. The SEM and TEM images of graphene are shown in Figure 6c,d. 

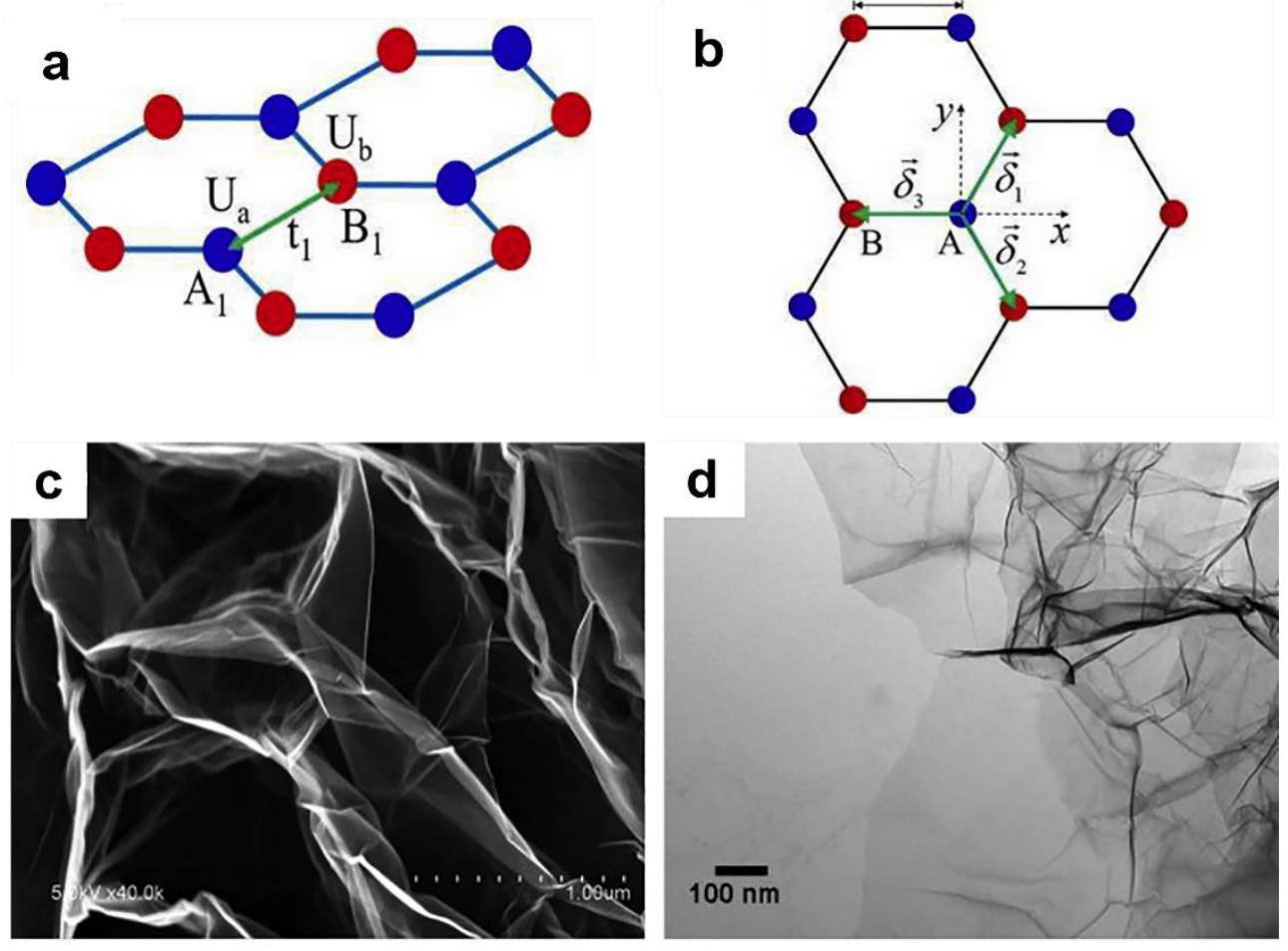

Figure 6. (a) and (b) Single-layer graphene lattice [56]. Copyright (c 2021 Elsevier Ltd. and Solid State Communications. (c) SEM images and (d) TEM images of graphene [57]. Copyright (C 2021 Published by Elsevier B.V. and Applied Surface Science.

Due to the unique Dirac cone band structure of graphene near the Fermi level, it has high carrier concentration and ballistic transport. Graphene (known as zero-gap semiconductor) can also be wrapped in other graphite materials to expand its application range [58]. Many properties of graphene have yet to be explored. The nonlinear optical properties of graphene in solution and the hydrogen absorption properties of monolayer and bilayer graphene are important issues. In addition to experimental research, there is still considerable space for theoretical research on various aspects of graphene, including the dependence of electronic structure, doping effect, and properties on the number of layers [59].

\subsection{Graphene-like Materials}

Graphene-like materials are solids formed by stacking monatomic layers or polyhedral layers. The atoms or polyhedrons in the layers are connected with each other by covalent bonds or ionic bonds, and the layers are connected by van der Waals force. Due to the weak interlayer van der Waals force, the layered van der Waals solid can be stripped into several layers or even single layers, becoming a two-dimensional layered graphite-like material.

The structural lattice of BN and graphene carbon are similar, like a honeycomb structure composed of $\mathrm{sp}^{2}$ hybrids. (see Figure 3a) [60]. The coordination of transition metal atoms and chalcogen elements in the sandwich lattice of layered TMD crystals plays an important role. [20]. From the coordination and oxidation state of the metal atoms, it can be judged whether the layered TMD is a semiconductor or a metal [61]. Compared with graphite and h-BN, although the $\mathrm{MoS}_{2}$ layer is also composed of hexagons, its atomic connections are alternately connected by Mo and $S_{2}$ atoms.

In layered $\mathrm{SnO}$ (see Figure 7a), the structure is layered in the [001] crystallographic orientation with a van der Waals gap of $2.52 \AA$ between the $\mathrm{Sn} 1 / 2-\mathrm{O}-\mathrm{Sn} 1 / 2$ sequence and adjacent $\mathrm{Sn}$ planes; in $\mathrm{SnTe}$ and $\mathrm{PbX}(\mathrm{X}=\mathrm{S}$, $\mathrm{Se}$, or $\mathrm{Te})$, the formation of crystallization is a cubic $\mathrm{NaCl}$ structure; whereas GeTe and SnTe have a rhombohedral structure [62] (Figure 7b). The structure of SnS2 as shown in Figure 7c, in which Sn atoms are located in 
the octahedron between two hexagonal closely packed S plates to constitute a sandwich structure [63].
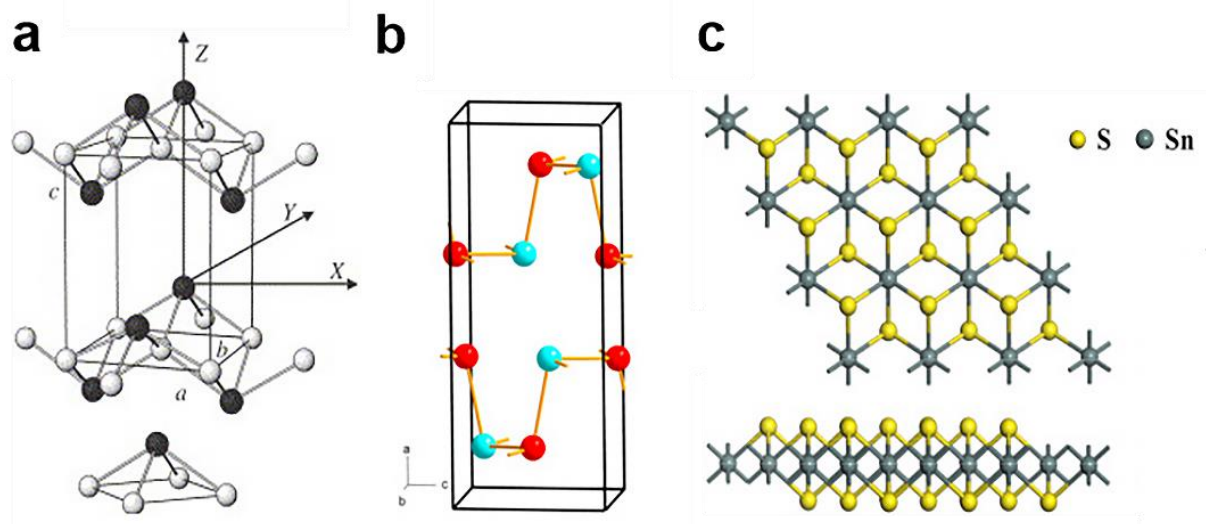

Figure 7. (a) Ball-and-stick model for litharge structure of SnO [64]. Copyright (C 2021 Elsevier B.V. and Physica B: Condensed Matter. (b) The Pnma orthorhombic structure of GeSe [65]. Copyright (C) 2021 Elsevier B.V. and The Chinese Ceramic Society. (c) Top view and side view of SnS 2 [66]. Copyright (C) 2021 Elsevier B.V. and Materials Chemistry and Physics.

There are many kinds of graphene-like materials. Due to the layered structure, some graphene-like materials show better properties than graphene.

\subsection{Carbon Nanotubes}

Carbon atoms can be combined in many ways to build structures with completely different properties. Several to dozens of concentric cylinders consisting of regular periodic interlayer spacing in MWCNTs are assembled at their centers. The interlayer spacing of MWCNTs is between 0.34 and $0.39 \mathrm{~nm}$ [67] (Figure 8). Both ends of MWCNTs are generally closed, and the ends are covered by dome-shaped semi-fullerene molecules (pentagonal defects), with axial dimensions ranging in size from $1 \mu \mathrm{m}$ to $3-4 \mathrm{~cm}$. The half-fullerene molecule (pentagonal ring defects) helps to close the cylinder at both ends.
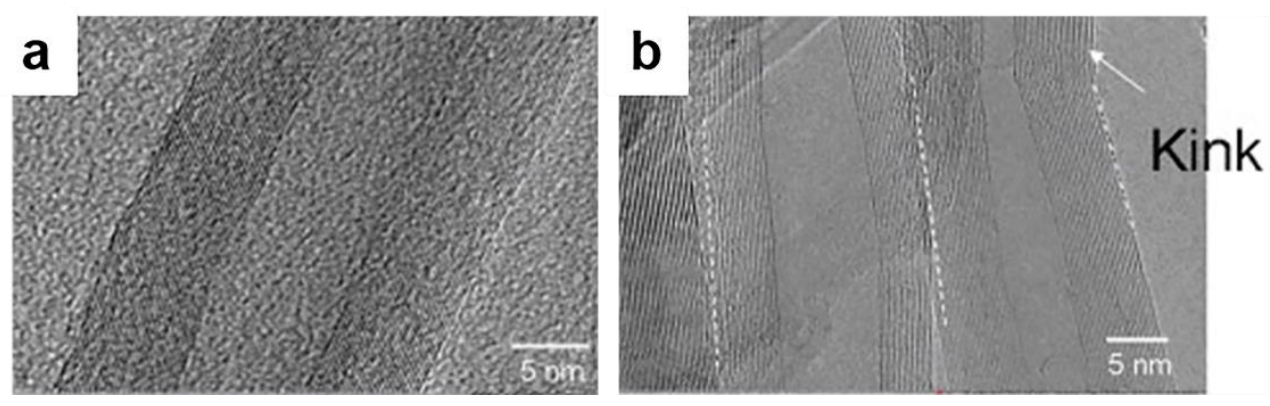

Figure 8. (a) HRTEM image of multi-shelled nanotube. (b) Multi-walled carbon nanotubes are welded together [68]. Copyright (C) 2021 Elsevier Ltd. and Carbon.

Compared to MWCNTs, the diameter of SWCNTs is between 0.4 and $3 \mathrm{~nm}$, and their lengths are usually in the $\mu \mathrm{m}$ range, and SWCNTs can be gathered together to form bundles (ropes). In the bundled structure, SWCNTs adopt a hexagonal organization, forming a crystal-like structure. Thus, SWCNTs are highly uniform and ideal molecular fibers. In addition, MWCNTs can be divided into Russian doll models and parchment models. The Russian doll model refers to the small CNTs nested in the largest CNTs, and the outer diameter is larger than the inner diameter. The model in which a simple graphene sheet rolls itself up like a roll of paper is called a parchment model.

Compared with SWCNTs, MWCNTs can be protected because they have a large number of carbon layers and have higher tensile strength. 
CNTs have many excellent properties due to their unique structural characteristics. Studies have shown that the modulus of elasticity of carbon nanotubes can reach 1 Tpa $[69,70]$, which is equivalent to that of diamond, and approximately five times higher than steel. The tensile strength of carbon nanotubes exceeds $5 \mathrm{GPa}$, exceeding the $2 \mathrm{GPa}$ tensile strength of high-strength metals [71]. In addition, carbon nanotubes have good thermal and chemical stability and excellent thermal conductivity and superconductivity [72], and these properties, especially their optical properties [73], demonstrate that carbon nanotubes have significant research value and developmental potential.

Wang et al. [74] simulated and calculated the conductivity and percolation threshold of aligned carbon nanotube composites. The study found that the electrical conductivity and percolation threshold of the composite material was dependent on the length, aspect ratio, and structure of the carbon nanotubes, and more specifically, the geometric size and structure of the carbon nanotubes.

$\mathrm{Hu}$ et al. [75] studied the effects of ordered carbon nanotubes on the low-temperature crack resistance of composite materials at low temperatures. The carbon nanotubes were oriented in a magnetic field, where the carbon fiber composite was prepared using the paramagnetic particles of ferroferric oxide, and the carbon nanotubes were aligned. The low-temperature mechanical properties of the composite material improved, and the thermal expansion coefficient decreased. Compared with pure resin, the thermal expansion coefficient of the carbon nanotube-oriented composite material was reduced by $41.6 \%$, and compared with a carbon fiber resin composite material, the microcrack density at low temperatures was reduced by $56.2 \%$.

Li and Dong [76] prepared epoxy resin/carbon nanotube composites using an electric field induction method. The carbon nanotubes were uniformly dispersed and arranged in the epoxy resin in an orderly manner along the electric field direction. When the content of carbon nanotubes was $2.5 \%$, the tensile strength of the material increased by $26.3 \%$. For carbon nanotubes, their structures may have defects or doped structures in addition to the common single wall and multi wall forms. Table 1 lists the effects of defects or doping on the properties of carbon materials.

Table 1. Structure and properties.

\begin{tabular}{|c|c|c|c|c|c|c|c|}
\hline \multirow{2}{*}{\multicolumn{2}{|c|}{$\begin{array}{l}\text { Carbon } \\
\text { Materials }\end{array}$}} & \multirow[b]{2}{*}{$\begin{array}{l}\text { Structural } \\
\text { Features }\end{array}$} & \multicolumn{3}{|c|}{ Performance } & \multirow[b]{2}{*}{$\begin{array}{c}\text { Optical } \\
\text { Properties }\end{array}$} & \multirow[b]{2}{*}{ Ref. } \\
\hline & & & $\begin{array}{l}\text { Mechanical } \\
\text { Properties }\end{array}$ & $\begin{array}{c}\text { Electrical } \\
\text { Properties }\end{array}$ & Magnetic & & \\
\hline \multirow{2}{*}{\multicolumn{2}{|c|}{ Carbon Fibers }} & Defective & $x$ & - & - & - & [77] \\
\hline & & Modification & $\sqrt{ }$ & - & - & - & [78] \\
\hline \multirow{2}{*}{\multicolumn{2}{|c|}{ Graphene }} & Defective & $x$ & - & $\sqrt{ }$ & - & {$[79,80]$} \\
\hline & & Doping & - & $\sqrt{ }$ & - & $\sqrt{ }$ & [81-83] \\
\hline \multirow{6}{*}{$\begin{array}{l}\text { Graphene-like } \\
\text { Materials }\end{array}$} & \multirow{2}{*}{$\mathrm{MoS}_{2}$} & Defective & $x$ & $\sqrt{ }$ & - & - & [84-87] \\
\hline & & Doping & $\sqrt{ }$ & $\sqrt{ }$ & & $\sqrt{ }$ & [88-90] \\
\hline & \multirow{2}{*}{$\mathrm{WS}_{2}$} & Defective & - & $x$ & $\sqrt{ }$ & - & [91-93] \\
\hline & & Doping & - & $\sqrt{ }$ & $\sqrt{ }$ & $\sqrt{ }$ & [94-96] \\
\hline & \multirow{2}{*}{$\mathrm{h}-\mathrm{BN}$} & Defective & - & $\times$ & - & - & [97] \\
\hline & & Doping & - & - & $\sqrt{ }$ & - & {$[98,99]$} \\
\hline \multirow{2}{*}{\multicolumn{2}{|c|}{ Carbon Nanotubes }} & Defective & $x$ & $\times$ & - & - & [100-102] \\
\hline & & Doping & $\sqrt{ }$ & $\sqrt{ }$ & $\sqrt{ }$ & $\sqrt{ }$ & [103-106] \\
\hline
\end{tabular}

Note: " $\sqrt{ }$ ": a positive change in this aspect; “ $\times$ ": a negative change in this respect; “-": no mention.

For all carbon materials, in addition to the conventional structure, there will be defects, doping, and other structural differences. For different carbon materials, the effects of defects and doping are different. For example, when carbon fiber has defects, its mechanical properties will decline accordingly, but for $\mathrm{MOS}_{2}$, the effect of defects on its mechanical properties is positive. We list the main performance changes of some defects or doped materials reported in recent years in Table 1. In addition to the properties noted in the table, defects and doping may also have a certain impact on the catalytic and photothermal 
properties of the material. Therefore, mastering the preparation methods and repair methods of carbon materials is an important breakthrough in its application field.

\section{Preparation of Carbon Materials}

\subsection{Carbon Fibers}

There are many methods to prepare carbon fibers, such as chemical vapor deposition (CVD), sol-gel, electrospinning, and so on. Compared with the electrospinning method, the CVD method is used less often for carbon fiber preparation. With the development of CVD, the properties of CVD-prepared carbon fibers or composite carbon fibers are getting better and better.

In 1985, Matsumura et al. prepared highly conductive graphite fibers by cracking cyanoacetylene on the surface of carbon fibers and then performing heat treatment, and their conductivity remained stable for a period of time. The scanning electron microscope image is shown in Figure 9a [107]. In 1993, with methane as the precursor, the pressure in the reaction chamber greater than 1 bar, and the growth rate greater than $0.3 \mathrm{~mm} / \mathrm{s}$, a carbon fiber with good performance was obtained. [108]. That study provides some guidance for the preparation of carbon fiber by the CVD method.
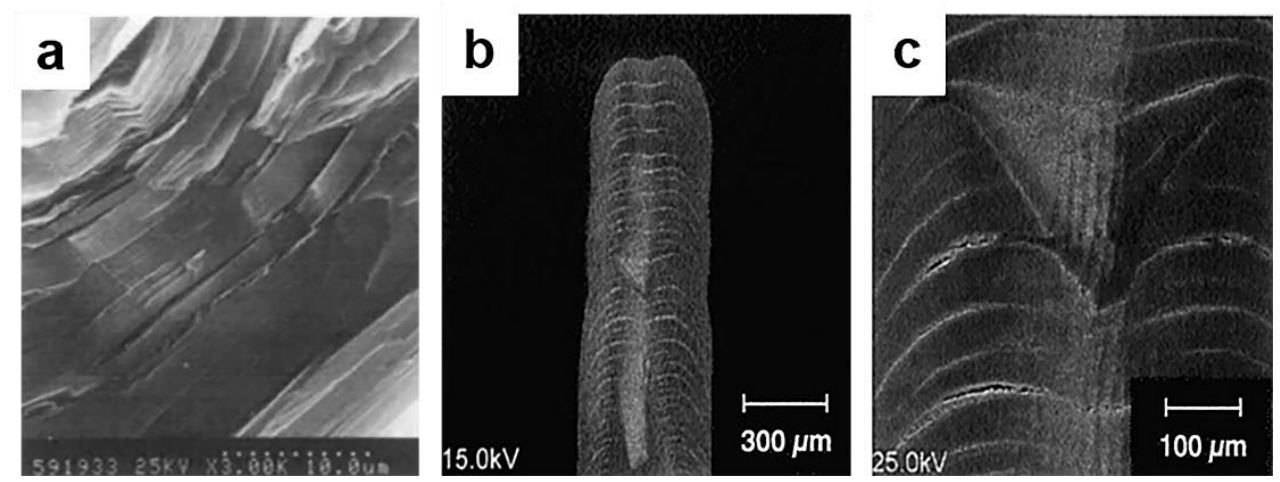

Figure 9. (a) SEM of the graphite fiber prepared by CVD of cyanoacetylene at $3000{ }^{\circ} \mathrm{C}$ on carbon fiber [107]. Copyright (C) 2021 Elsevier B.V. and Synthetic Metals. (b) Fiber profile, and (c) stripe microstructure at center of fiber [108]. Copyright (C) 2021 Elsevier Ltd. and Carbon.

V.K.Varadan et al. reported that the use of microwave CVD may avoid the use of toxic impurities contained in traditional methods [109]. Kang et al. observed a lamellar microstructure parallel to the deposition surface in carbon fibers prepared by methane laser CVD [108]. As shown in Figure 9b, when fibers were deposited at peak temperatures higher than approximately $2100{ }^{\circ} \mathrm{C}$, the deposition center is usually concave, i.e., the tip of the fiber is similar to a volcano. From longitudinal section micrographs shown in Figure 9c, it can be observed that there is a striped structure in the central part of the fiber along the axial.

In recent years, some people have started to combine chemical vapor deposition with other fiber preparation methods (electrospinning, wet spinning, etc.) to prepare modified fibers. Feng et al. combined electrospinning technology with CVD to prepare superhydrophobic carbon fibers (SCFS), which still have superhydrophobic properties at $97^{\circ} \mathrm{C}$ and maintain excellent superhydrophobic properties after being immersed in strong acid, strong alkali, and organic solvent for 120 days [110]. For long-term reuse under various harsh conditions, they have promising application.

The CVD process can also be used for the modification of carbon fibers. Li et al. modified carbon fiber by CVD [111]. Rong et al. attached carbon nanotubes onto carbon fibers to increase the effective area. Figure 10 is an SEM image of a layer of CNTs coated on a carbon fiber by a CVD method [112]. 

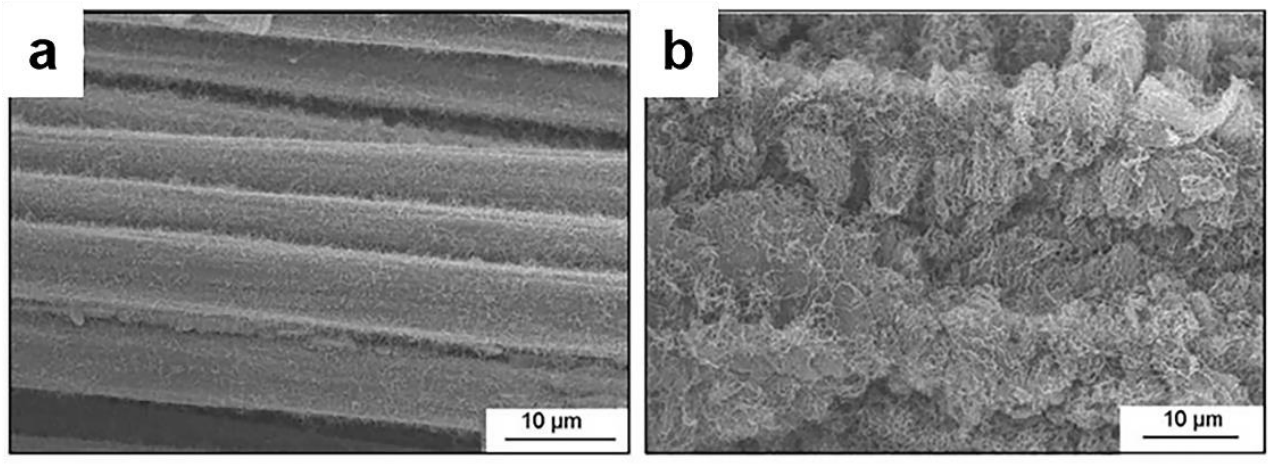

Figure 10. SEM images of the carbon fiber grown with (a) traditional thermal CVD and (b) modified thermal CVD [113]. Copyright ( 2021 Elsevier B.V. and New Carbon Materials.

\subsection{Graphene}

Currently, there are many different processes for preparing graphene, such as mechanical exfoliation, chemical methods [114], SiC graphitization epitaxial growth [115], and chemical vapor deposition (CVD) [116]. Usually, the CVD method uses copper as the substrate for growing grapheme [117]. CVD is one of the commonly used methods in the preparation of graphene; it can prepare high-quality graphene on a large area.

In 1975, the deposition of single-layer graphite material on Pt by CVD was first reported [118]. Subsequently, Eisenberg and Blackley reported the formation of a graphite layer on nickel (111) [119]. In 1984, researchers carried out IR, for what may be the first graphene grown on the metal surface [86]. In 2006, camphor (terpenoids, white transparent solids with the chemical formula of $\mathrm{C}_{10} \mathrm{H}_{16} \mathrm{O}$ ) was first tried as precursor material. Figure 11 shows TEM image of planer few layer graphene (PFLG) film [120].

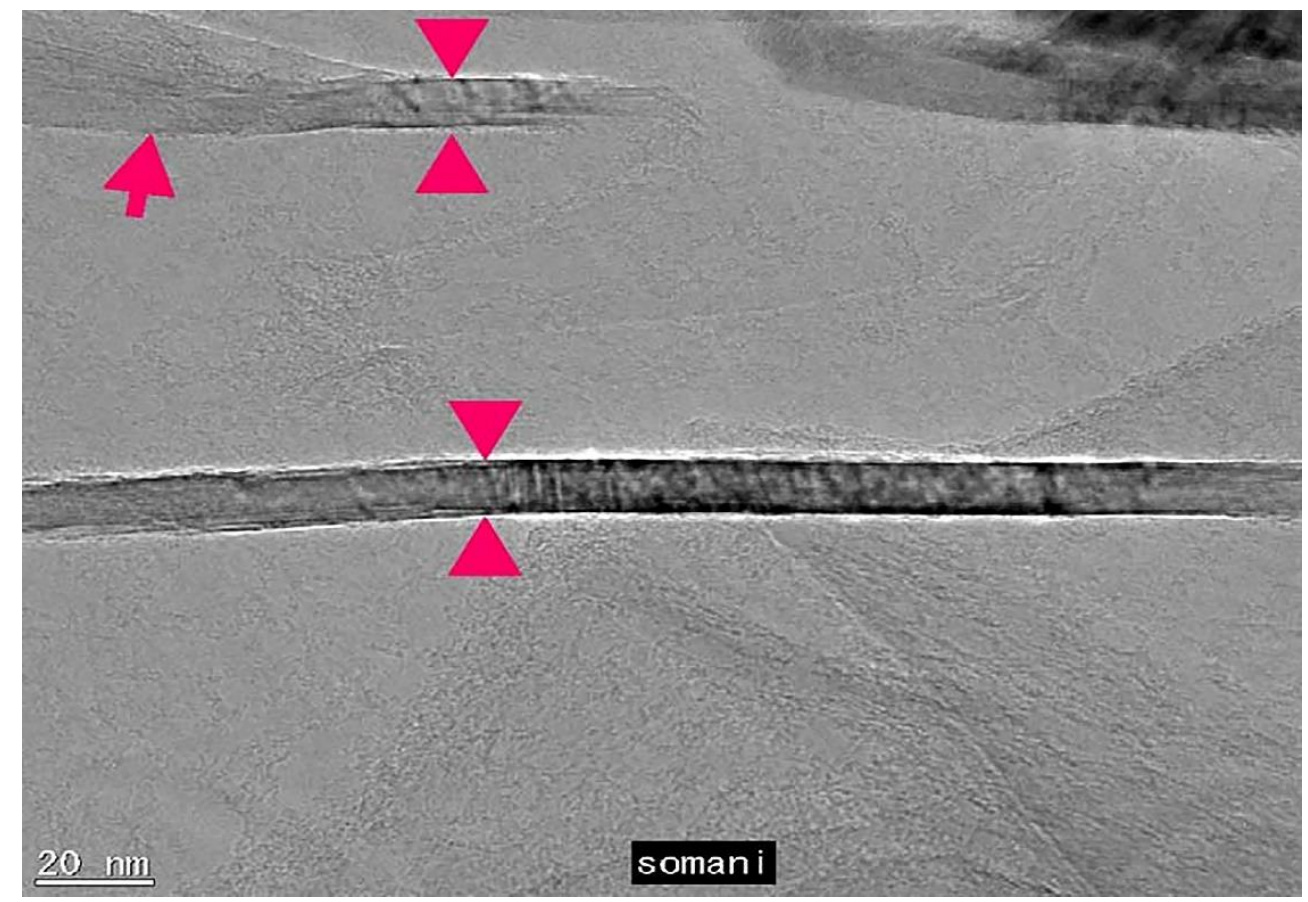

Figure 11. HR-TEM image of PFLG film [120]. Copyright (c) 2021 Elsevier B.V. and Chemical Physics Letters.

CVD has many different processes, which can be divided into hot wall, cold wall, or plasma enhancement (PECVD) according to the required materials, precursors, and structures. Graphene is mainly formed on copper film through a cold wall system. 
Recently, Soriadi et al. reported the growth of graphene for the varied thicknesses of 100-600 nm by using a cold-wall CVD reactor [121]. Das et al. [122] used cold-wall chemical vapor deposition to prepare graphene, changing the nucleation density and average size by changing the growth parameters. They found that when the temperature was $1000{ }^{\circ} \mathrm{C}$ and the pressure was 700 Torr, reducing the ratio of $\mathrm{CH}_{4}: \mathrm{H}_{2}$ or reducing the concentration at a fixed ratio would reduce the growth rate of graphene films. The change of the $\mathrm{CH}_{4}: \mathrm{H}_{2}$ ratio had the greatest effect on the nucleation density. It was also found that the boundary morphology of graphene microcrystals depends on the growth conditions; with an increase in effective carbon deposition rate, the process shifts from irregular/serrated to convex hexagon to regular hexagon. This observation shows that the diffusion of $\mathrm{C}$ adsorbed atoms along the edge of the growing graphene microcrystals may play an important role in the morphological evolution of graphene nuclei.

Through experiments and computational fluid dynamics (CFD) simulation, Jia et al. found that the cold-wall CVD system can inhibit the gas phase reaction more than the hotwall CVD system and can produce super clean graphene [123]. In contrast, the cold-wall system reduces the gas phase temperature because the heating is concentrated on the $\mathrm{Cu}$ substrate, which inhibits the formation of amorphous carbon. The reduction of amorphous carbon can be clearly seen by TEM.

In the future, the industry will emphasize the uniformity, size, growth rate, and transferability of graphene films, and its feasible mass production methods will be widely discussed in terms of capacity, output, cost, equipment, and industrial scale production line. The challenge of how to use simulation to obtain the optimal process conditions and commercialization of large-scale production still needs to be solved. Because the availability of clean surfaces will improve the performance of graphene for CVD and promote the discovery of new applications, the development of ultra-clean graphene will be more widely discussed in the future.

\subsection{Graphene-like Materials}

The preparation methods of graphene-like materials are the same as those of graphene. Mechanical stripping and liquid phase stripping are two of the commonly used methods in the preparation of layered samples. Separate sheets are separated from stacked twodimensional layered crystals by breaking the weak van der Waals bond between layers. However, in order to synthesize two-dimensional layered materials on a large scale, CVD has been favored by researchers, which is expected to control the number of layers and crystal structure.

Müller et al. reported the growth of hexagonal boron nitride (h-BN) on a Pt surface as indicated by low-energy electron diffraction (LEED) [124]. In 2011, Sun et al. directly synthesized a carbon film with graphene properties through a chemical vapor deposition method at a temperature of $1000^{\circ} \mathrm{C}$ without any metal catalyst [125]. The film thickness can be controlled by modifying the growth conditions.

Shi et al. [126] used atmospheric chemical vapor deposition to synthesize hexagonal boron nitride (h-BN) films and proved that the h-BN film followed the morphology of the nickel surface after growth. Qin et al. [127] chose to use CVD to synthesize h-BN films under ambient pressure. Most of the samples prepared by this method are composed of several atomic layers, but a small amount of single-layer h-BN flakes are also obtained. It can be concluded that the size of the h-BN sheet is approximately $0.8-2.5 \mu \mathrm{m}$. This method has great potential for mass production of a small amount of atomic layer boron nitride sheets.

Three-dimensional (3D) $\mathrm{MX}_{2}$ compounds display important properties such as semiconductivity, half-metallic magnetism, or charge density wave [61]. Lee et al. used $\mathrm{MoO}_{3}$ and $\mathrm{S}$ as reactants and successfully synthesized an $\mathrm{MoS}_{2}$ layer on $\mathrm{SiO}_{2}$ by chemical vapor deposition. The characterization also proved that the $\mathrm{MoS}_{2}$ synthesized by this method has high crystallinity (Figure 12b,c) [128]. The in-plane X-ray diffraction (XRD) profile for 
the $\mathrm{MoS}_{2}$ monolayer synthesized by the CVD method is shown in Figure 12d. This method can also grow other transition metal dihalides.

a

$\bullet \bullet \bullet \bullet \bullet \bullet \bullet$

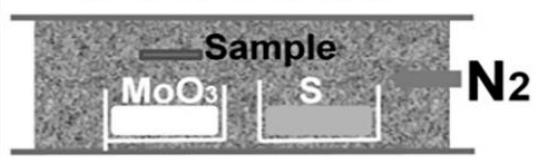

$\bullet \bullet \bullet \bullet \bullet \bullet \bullet ~$

C

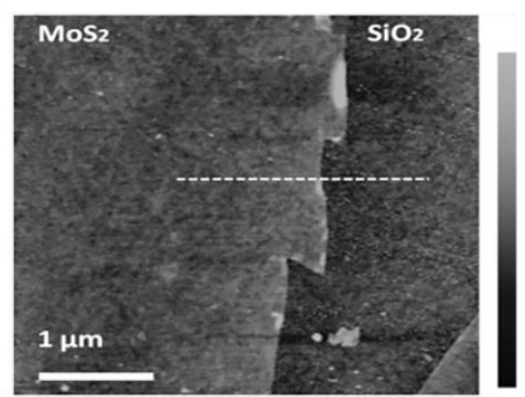

b

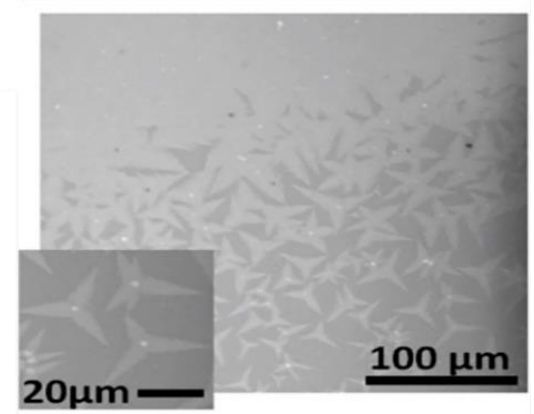

d

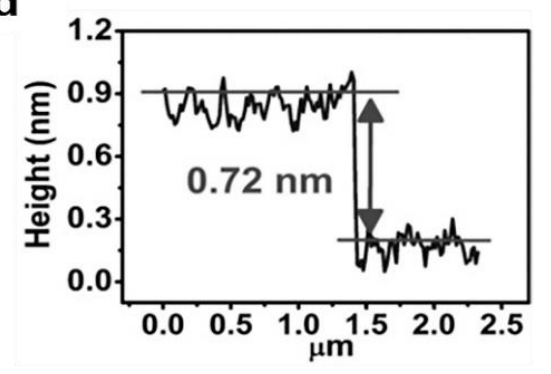

Figure 12. (a) Schematic illustration for the experimental set-up; (b) HRTEM image of $\mathrm{MoS}_{2}$ monolayer; (c) enlarged HR-TEM image of the marked area in figure (c) with an inset showing the SAED pattern; (d) in-plane XRD result for the $\mathrm{MoS}_{2}$ monolayer [128]. Copyright @ 2021 WILEY-VCH Verlag $\mathrm{GmbH} \&$ Co. KGaA, Weinheim.

Alagh was the first to propose that aerosols can be used to assist the chemical vapor deposition method (AA-CVD), combining it with the CVD method without $\mathrm{H}_{2}$ atmospheric pressure, to realize the simple synthesis of two-dimensional layered $\mathrm{WS}_{2}$ nanosheets on the one-dimensional $\mathrm{WS}_{2}$ nanostructure [129]. The experimental steps are shown in Figure 13a and c: first, $\mathrm{WO}_{3}$ or nanoneedles are directly deposited on alumina substrate, and then vulcanization treatment is carried out. Figure 13b shows the SEM image of the material before vulcanization. Vulcanization promotes the growth of $\mathrm{WS}_{2}$ (Figure 13d).

a

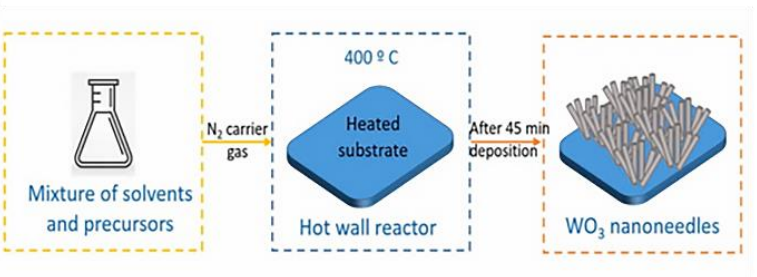

C

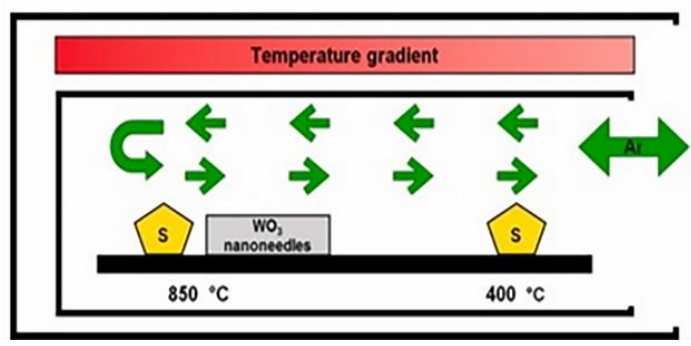

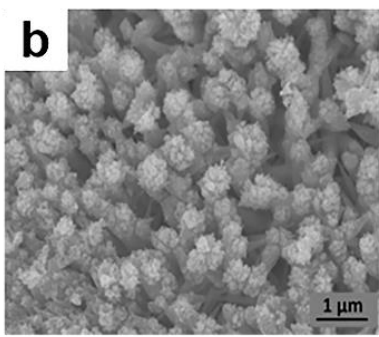

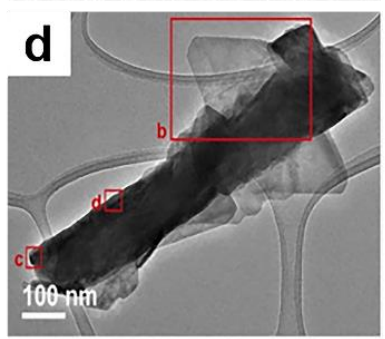

Figure 13. (a) AA-CVD synthesis of $\mathrm{WO}_{3}$ nanomaterials; (b) CVD synthesis of $\mathrm{WS}_{2}$ nanomaterials; (c) SEM images of $\mathrm{WO}_{3}$ nanorods; (d) TEM image of $\mathrm{WS}_{2}$ nanoneedles. [129] Copyright (C) 2021 Elsevier B.V. and Sensors and Actuators B: Chemical. 
So far, in addition to TMD, there are few studies on metal sulfides, and the technology for large-scale continuous production of two-dimensional materials has yet to be developed. Therefore, the most important task at present is to develop and realize large-scale production of graphene-like materials. From the existing methods, in addition to stripping, chemical vapor deposition and chemical methods are very promising. However, there are few studies on the preparation of graphene-like materials by combining simulation and chemical vapor deposition. If it can be used a little, it is very helpful to prepare graphene-like materials with good quality.

\subsection{Carbon Nanotubes}

When choosing a method to prepare the CNTs, CVD methods are particularly attractive because they can be easily scaled up when strict, custom control of the deposit structure is required. Commonly used carbon sources are $\mathrm{CH}_{4}$, carbon monoxide and acetylene. Carbon nanotubes of different structures can be obtained according to the adjustment of temperature and pressure. In this section, the factors affecting the preparation of carbon nanotubes by chemical vapor deposition are reviewed from three aspects: catalyst and support material, carbon precursor, and depositional conditions.

\subsubsection{Catalyst and Support Material}

Zhang et al. [130] used $\mathrm{CH}_{4}$ as a carbon source and nickel as a catalyst to form tubular and multi-walled carbon nanotubes. In their research, they found that at $600{ }^{\circ} \mathrm{C}$, the formation of carbon nanotubes is the greatest. Microwave radiation and nickel catalyst play key roles in the growth process. Through X-ray diffraction (XRD) and Raman analysis (Figure 14), the resulting carbon nanotube structure is perfect, and the growth process follows the cutting-edge growth mechanism.
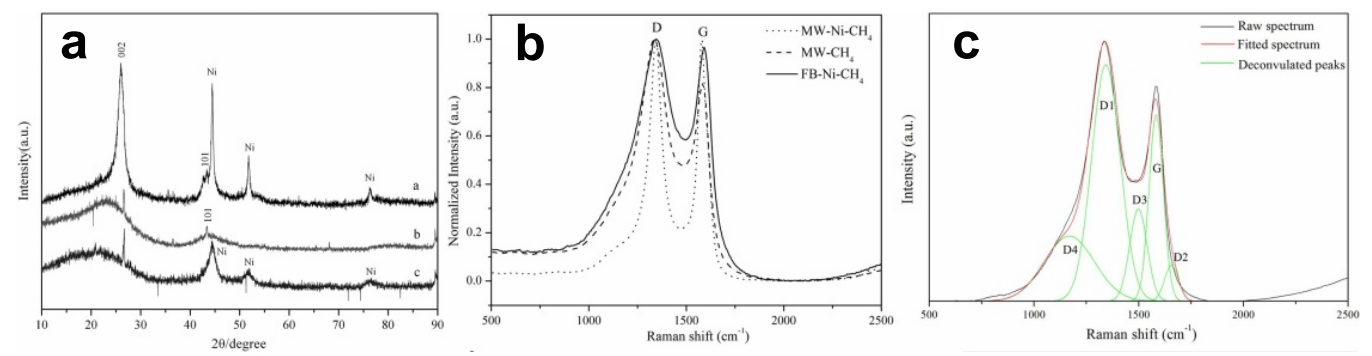

Figure 14. (a) X-ray diffraction pattern of pine nut shell (PNS) coke at $600^{\circ} \mathrm{C}$ : (i) nickel-containing catalyst during microwave radiation, (ii) nickel-free catalyst during microwave radiation, and (iii) nickelcontaining catalyst in fixed bed; (b) normalized Raman spectra; (c) typical deconvoluted Raman spectra of carbon nanotubes (CNTs) [130]. Copyright (c) 2021 Elsevier B.V. and Diamond and Related Materials.

Shukrullah et al. [131] synthesized multi-walled carbon nanotubes by cracking ethylene gas molecules in a fluidized bed CVD reaction chamber with $\mathrm{Fe}_{2} \mathrm{O}_{3} / \mathrm{Al}_{2} \mathrm{O}_{3}$ as composite catalyst; the schematic diagram of the process is shown in Figure 15. They calculated the adsorption capacity of carbon nanotubes and amine functionalized carbon nanotubes from the penetration curve of carbon nanotubes in the growth state. In other words, among all the tested samples, the $\mathrm{CO}_{2}$ adsorption capacity of amine-functionalized MWCNTS is the highest, approximately $129 \mathrm{~cm}^{3} / \mathrm{g}$. 


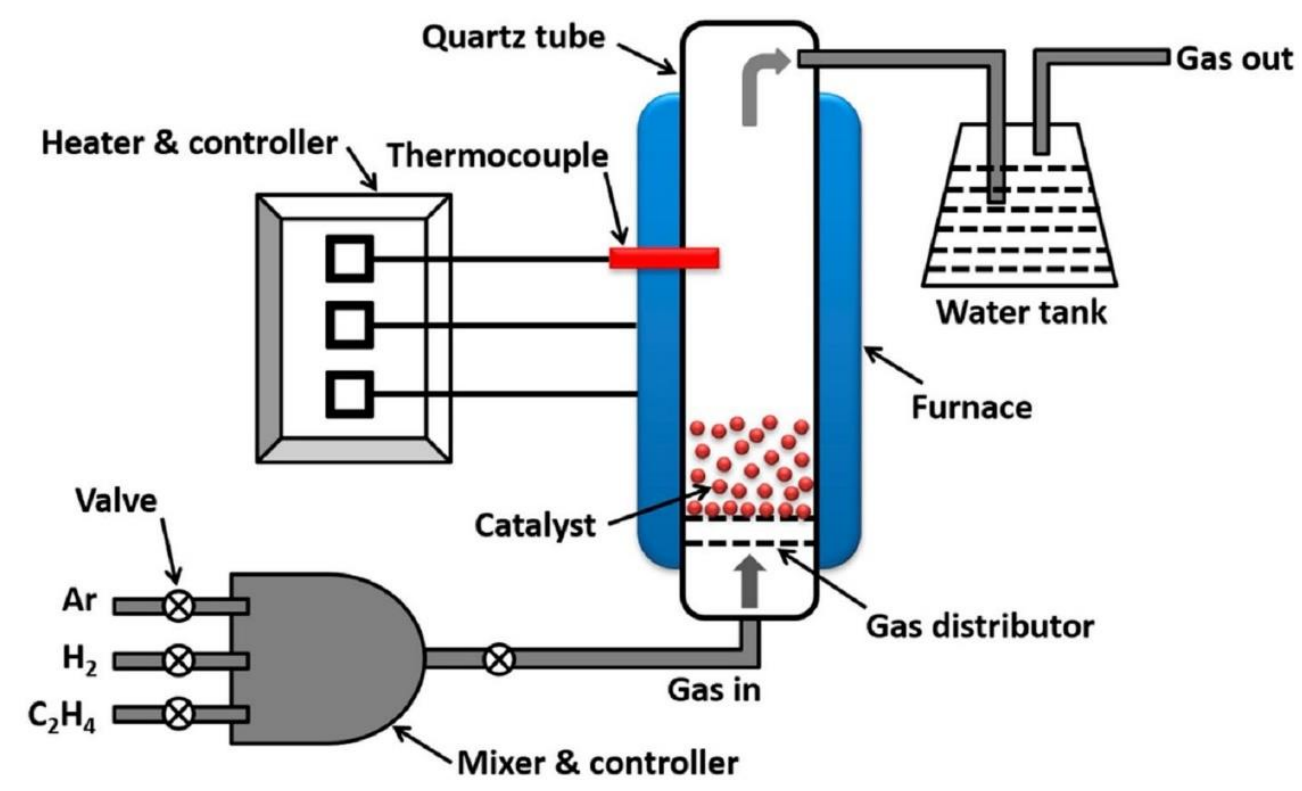

Figure 15. Schematic of fluidized bed CVD setup [131].

Wang et al. [132] discovered that the addition of iron in the catalytic process will lead to the negative charge of the grown carbon nanotubes; in addition, they also found that if different external electric fields were applied, the chirality of carbon nanotubes would be significantly affected by the change of Fermi level of iron catalyst.

In 2016, Li and Zhang [133] used Fe-Cu catalysts to selectively grow single-walled and multi-walled carbon nanotubes. By introducing a certain amount of $\mathrm{Cu}$ to inhibit the diffusion of Fe nanoparticles, the growth of single-walled carbon nanotubes can be realized; multi-walled carbon nanotubes can then be obtained by introducing a Cu catalyst on $\mathrm{Fe} / \mathrm{Al}_{2} \mathrm{O}_{3}$.

In 2018, Shah et al. [134] reported the growth of MWCNTs on a $\mathrm{Pt}-\mathrm{W}$ catalyst at $800{ }^{\circ} \mathrm{C}$ using the CVD technique. In the CVD system, the growth of nanotubes is usually controlled by the size of catalyst particles. If the catalyst particle density is high and the catalyst activity is widely distributed, linear and wavy multi walled carbon nanotubes are formed, whereas the formation of spiral/curly multi walled carbon nanotubes is usually explained based on the interaction between specific catalyst particles and growing nanostructures. The HRTEM images clearly revealed MWCNT formation with no lateral carbon deposits. Raman analysis also suggested that the concentration of defective molecules was low in the sample. It provides a basis for the new research field of carbon nanotube synthesis and its application in the electronic industry.

Presently, researchers have proposed a variety of purification methods for carbon nanotubes, which can be roughly divided into two methods: physical and chemical. The physical method mainly separates impurities and carbon nanotubes based on their physical properties. For example, single-walled carbon nanotubes prepared by arc or laser methodology are purified by microfiltration, and the final product is separated into pure SWNTs, fullerenes, carbon nanospheres, and polyaromatic carbon [135]. Spatial exclusion chromatography (SEC) is also commonly used as a physical purification method [136], with the advantages of high efficiency and fast separation, and this method is expected to be widely implemented in actual production. The chemical method primarily uses carbon nanotubes and different reactions of impurities and oxidizing substances to achieve purification. Common methods include dry oxidation [137], wet reflux oxidation [138], high temperature hydrogen treatments [39,40], and graphite intercalation compounds [139]. Zhao et al. found that the content of nanotubes increased when monitored by scanning electron microscope in the purification process with an increase in purification [137]. Magnetism was studied by using electron spin resonance (ESR). Two samples are used in 
electron spin resonance measurements of MWNT and SWNT; one is dispersed in hexane to form loosely contacted tubules, and the other is dried deposited tubules to achieve a tightly contacted tubule state. By using these samples, it was found that the electron spin resonance alignment is closely related to the contact between nanotubes. However, the chemical purification method can cause defects in the carbon nanotube structures during treatment, limiting the production of terminal and intertwined products.

Many impurities, such as amorphous carbon and metal particles, may be introduced in the process of synthesizing carbon nanotubes. Therefore, the purification stage in the late preparation stage is still very important to the purity of the product.

There are many reports on the purification method of CNTs. One of the most effective methods is to maintain a temperature of $750{ }^{\circ} \mathrm{C}$ for oxidation in an ordinary atmospheric environment. For pure CNTs, the oxidation stage is crucial. The use of $\mathrm{KMnO}_{4} / \mathrm{H}_{2} \mathrm{SO}_{4}$ mixed solution for liquid phase oxidation is also a feasible purification method. Although this method can obtain ultra-pure carbon nanotubes, the carbon nanotubes may be severely damaged in the end. Some have also proposed a purification method for graphite intercalation. According to previous studies, the bromine resistance of carbon nanotubes is not as good as that of carbon nanoparticles [140-144]. Hou et al. [145] proposed a process for efficient purification of carbon nanotubes and improved the multi-step purification process. The first step of this purification process is to obtain well dispersed nanotube structures, and the raw materials were subjected to ultrasonic and heat treatment. They were then soaked in bromine water at $90{ }^{\circ} \mathrm{C}$ for $3 \mathrm{~h}$ and kept heated in the open air for $45 \mathrm{~min}$ to $520^{\circ} \mathrm{C}$. Finally, the remaining powder was immersed in $5 \mathrm{~m}$ hydrochloric acid at room temperature to remove metal particles. The TEM image of the final synthesized product is shown in Figure 16.
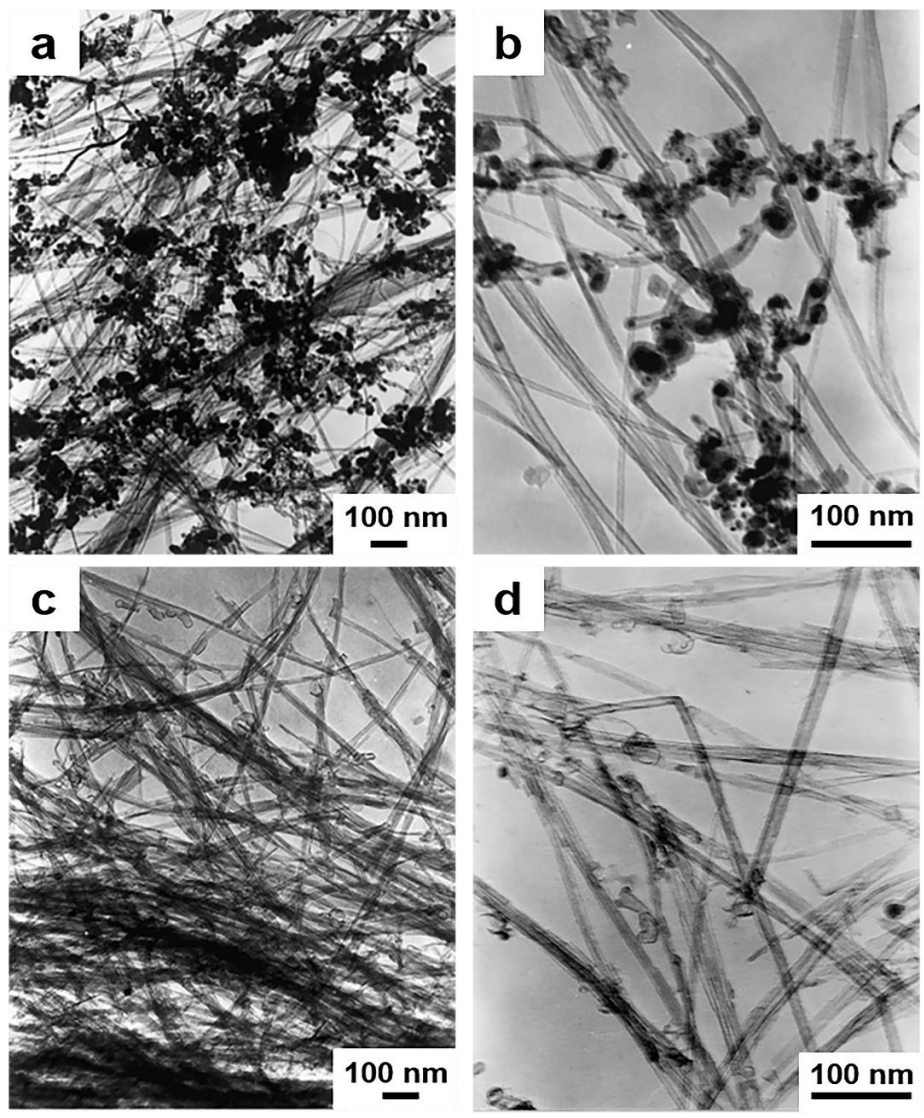

Figure 16. TEM images of the as-synthesized MWCNT product (a), the purified MWNTs without bromination (b), the purified MWNTs with bromination (c), and the purified MWNTs with bromination (d), showing some of the MWNT tips [145]. Copyright (C) 2021 Elsevier Science B.V. and Carbon. 
One of the biggest purification challenges is the purification of single-walled carbon nanotubes (SWNTs). Strong et al. studied a simple and relatively cheap SWNTs purification method [146]. Their method includes two steps: oxidative heat treatment and pickling. The purpose of the oxidation heat treatment stage is to oxidize and pickle the metal catalyst to achieve the purpose of removing the oxidant [147]. Li et al. [148] synthesized SWCNTs through the catalytic decomposition of hydrocarbons, and their analysis showed that the resulting product had amorphous carbon and catalyst particles. They then ensured that the vapor-grown carbon nanofibers and multi-walled carbon nanotubes are removed from SWCNTs without damaging them. The yield of SWCNTs purified by this method is $40 \%$, and the purity is approximately $95 \%$.

Chattopadhyay et al. [149] used a one-to-one mixture of hydrofluoric acid and nitric acid to purify the SWNT soot obtained by ultrasonic treatment. Dillon et al. [144] used hot-water to treat partial oxidation and $\mathrm{HCl}$ solvent oxide at $700{ }^{\circ} \mathrm{C}$, but some amorphous carbon and metal particles were still observed. Therefore, the removal of the metal catalyst by heating the material to a temperature at which the metal can evaporate is also a purification method [147]. High-temperature annealing can also remove the surface oxygen of the carbon nanotube material to achieve purification [150]. Andrews et al. [151] proposed that high temperature annealing is an effective way to purify carbon nanotubes. Chen et al. [152] reported a three-step process to purify multi-walled carbon nanotubes using $\mathrm{Ni}-\mathrm{Mg}-\mathrm{O}$ as a catalyst. For the third purification step, $510^{\circ} \mathrm{C}$ was chosen as the optimal nanotube burning temperature for eliminating non-nanotube carbon materials. This temperature was consistent with the results obtained by Colomer et al. [136], who determined that $500{ }^{\circ} \mathrm{C}$ was the optimal temperature. The purity of the purified MWNTs is more than $96 \%$ without damage. Biró et al. [153] used dry and wet chemical methods to remove unwanted catalysts. However, wet oxidation will cause relatively moderate damage to the outer wall of the carbon nanotubes, and because the metal particles are wrapped in the center of the carbon nanotubes, they cannot be removed even if the treatment is repeated.

So far, the method of purifying carbon nanotubes is still being discussed. Choosing an appropriate purification method is very important for the later application of carbon nanotubes. At the same time, a purification method with simple operation, low price, low energy consumption, and high purification efficiency is being explored and pursued by everyone.

\subsubsection{Carbon Precursor}

A traditional CVD technique was developed to produce a high CNT yield by multiplying the reactors in mostly three-quartz tubes [154]. In that design, the preparation of carbon nanotubes is achieved by single or multiple quartz tubes. Using high-purity $\mathrm{CH}_{4}$ as a carbon source and Fe as a catalyst, carbon nanotubes with an average diameter of 30 and $24 \mathrm{~nm}$ were produced at $650{ }^{\circ} \mathrm{C}$. This design not only improves the yield and quality, but also reduces the loss of energy consumption.

Another investigation assessed the gaseous and condensate [155] products of ethanol decomposition during the synthesis of SWCNTs by aerosol chemical vapor deposition (floating catalyst CVD). Analysis shows that using $\mathrm{CO}$ and $\mathrm{CH}_{4}$ as a mixed carbon source can produce relatively pure carbon nanotubes. The yield of carbon nanotubes produced by catalytic CO disproportionation is higher. Research has found that carbon deposition on the reactor wall plays an important role in the process of preparing carbon nanotubes.

Tripathi et al. [156] found that carbon nanomaterials can be made from plastic waste. As shown in Figure 17, plastic waste and SS316 metal tubes are used to grow carbon nanotubes, whereas the laboratory uses a centrifuge tube made of polypropylene as a carbon source. The metal tube can be used as a reactor or as a catalyst, and carbon nanotubes of good quality can be prepared under given conditions. 


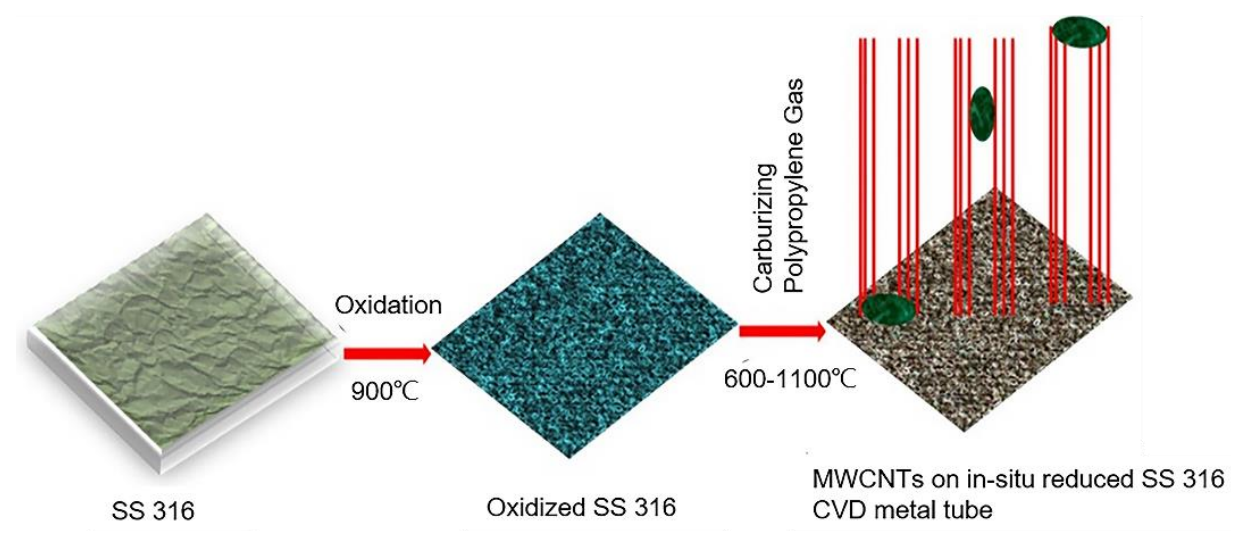

Figure 17. Mechanism of multi-walled carbon nanotube (MWCNT) growth using plastic waste and a stainless steel 316 (SS 316) metal tube [156].

Recent studies have shown that acetonitrile reversibly modulates the SWCNT diameter during CVD growth [157]. The researchers proposed non-equilibrium quantum chemical molecular dynamics simulations to explain the mechanism of this phenomenon. When single-walled carbon nanotubes nucleate, free radicals derived from acetonitrile will actively absorb hydrogen from the surface of the hydrocarbon. This process will reduce the overall surface carbon density; the release of hydrogen during the nucleation process accelerates the single-walled carbon. The nucleation kinetics of the nanotubes combined with the lower surface carbon density results in single-walled carbon nanotubes with a narrower diameter in the presence of acetonitrile.

Li et al. [158] proposed that the formation of carbon nanotubes depends on the chemical structure of hydrocarbon precursors. They believed that aromatic molecules are conducive to the preparation of single-walled carbon nanotubes, whereas aliphatic molecules form multi-walled carbon nanotubes. However, the formation of single-walled carbon nanotubes or multi-walled carbon nanotubes is not only dependent on the carbon source, but also closely related to other growth conditions (such as catalyst type, temperature, and gas flow rate).

\subsubsection{Depositional Condition}

Polycrystalline carbon nanowires (P-CNWs) [32] have been synthesized using CVD with $\mathrm{C}_{2} \mathrm{H}_{4}$ as the carbon source and Ni particles distributed in porous $\mathrm{Si}_{3} \mathrm{~N}_{4}$ ceramics as the growth seeds at $700{ }^{\circ} \mathrm{C}$. The obtained P-CNW shows that the solid core and base surface of the graphite nanosheets are perpendicular to the spool. In addition, the elevated growth temperature promotes the formation of hollow carbon nanotubes at $750{ }^{\circ} \mathrm{C}$ and amorphous carbon above $800{ }^{\circ} \mathrm{C}$, thereby changing the conductivity and dielectric properties of carbonreinforced $\mathrm{Si}_{3} \mathrm{~N}_{4}$ composite ceramics.

Shukrullah et al. [159] used $\mathrm{Fe}_{2} \mathrm{O}_{3} / \mathrm{Al}_{2} \mathrm{O}_{3}$ as the catalytic support and discussed the ethylene flow rate and the entire process time for the growth of CNTs in a fluidized bed chemical vapor deposition (FBCVD) reactor at a temperature of $800^{\circ} \mathrm{C}$. The experimental results found that the best growth effect can be obtained when the ethylene flow rate is $100 \mathrm{sccm}$ and the CVD process time is $60 \mathrm{~min}$. At present, there are a large number of articles reporting CNTs grown by thermal CVD systems [160]. Many studies have shown that reaction acidity, chemical properties of catalyst nanoparticles, and carbon precursors are important parameters in the preparation of CNTs.

Some researchers found that when the reaction temperature was below $400{ }^{\circ} \mathrm{C}$, the defect concentration of CNTs grown was very high, but the diameter was large, approximately $20 \mathrm{~nm}$. However, when the reaction temperature was $400{ }^{\circ} \mathrm{C}$, the CNTs obtained had no obvious defects and were approximately $12 \mathrm{~nm}$ in diameter. If a single metal or bimetal catalyst is selected, WMCNTs can be synthesized at $600^{\circ} \mathrm{C}$ in a CVD system with acetylene as precursor [161]. The catalysts were prepared by two methods, precipitation and solgel, with two different carriers, $\mathrm{MgO}$ and $\mathrm{Al}_{2} \mathrm{O}_{3}$. The highest yield of $800 \%$ was 
achieved by a two-component $\mathrm{NiO} / \mathrm{Co}_{2} \mathrm{O}_{3} / \mathrm{MgO}$ catalyst. These MWCNTs were smooth and unidirectional. Their tube diameter was approximately $20 \mathrm{~nm}$. The results show that the use of a single-component catalyst can promote the uniform growth of nanotubes and obtain smaller diameters; after being treated with concentrated nitric acid under reflux and washing conditions, the specific surface area of the nanotubes will increase and the average pore diameter will decrease. On the $\mathrm{NiO} / \mathrm{Co}_{2} \mathrm{O}_{3} / \mathrm{MgO}$ catalyst, multi-walled carbon nanotubes with the largest specific surface area $\left(305 \mathrm{~m}^{2} / \mathrm{g}\right)$ and average pore size $\left(26 \mathrm{~m}^{2} / \mathrm{g}\right)$ with large structural adsorption characteristics were grown.

Li et al. [162] proposed that $\mathrm{MgO}$ is a good carrier for the preparation of carbon nanotubes by chemical vapor deposition. It can not only increase the yield, but also obtain carbon nanotubes with fewer impurities and controllable diameter by appropriately controlling the reaction temperature, catalyst, and gas flow rate and other reaction parameters. At the same time, $\mathrm{MgO}$ can be easily removed with weak acid without destroying the structure and quality of the product. If Mo salt is added as an auxiliary catalyst, the yield can be increased to approximately $120 \%$.

There are some points that should be paid attention to when preparing carbon materials and graphene-like materials by the CVD method, such as the selection of precursors, deposition conditions, catalysts, and so on. The substrate has a certain relationship with the catalyst. In the process of preparing carbon materials and graphene-like materials by CVD, sometimes the substrate acts as the catalyst, and different choices will lead to differences in the structure and properties of the prepared materials. Therefore, summarizing and selecting the necessary preparation conditions is a major premise to determining the properties and application fields of materials. Table 2 lists the more basic conditions and the corresponding material selection. According to the different combinations of the three, the effects of different air velocity, temperature, pressure, and reaction time are different. Researchers should explore green and efficient preparation methods according to materials and their applications. Facing such a variety of choices, we need to summarize and explore more carefully.

Table 2. Main conditions for preparation of carbon materials and graphene-like materials by CVD.

\begin{tabular}{|c|c|c|c|c|c|}
\hline Material & Condition & Precursor & Substrate & Catalysts & Ref. \\
\hline \multicolumn{2}{|c|}{ Carbon Fibers } & $\mathrm{CH}_{4}, \mathrm{C}_{2} \mathrm{H}_{2}, \mathrm{C}_{3} \mathrm{H}_{8}$ & $\mathrm{Ni}, \mathrm{Ni} / \mathrm{Al}_{2} \mathrm{O}_{3}, \mathrm{SiO}_{2} / \mathrm{Si}$ & $\mathrm{SiC}, \mathrm{Cu}$ & {$[73,108,160-162]$} \\
\hline \multicolumn{2}{|c|}{ Graphene } & $\mathrm{CH}_{4} / \mathrm{H}_{2}, \mathrm{CH}_{4} / \mathrm{H}_{2} / \mathrm{Ar}$ & $\begin{array}{c}\mathrm{Fe}, \mathrm{Si} / \mathrm{SiO}_{2}, \mathrm{Ni}, \mathrm{Cu} / \mathrm{W}, \\
\mathrm{Fe}_{2} \mathrm{O}_{3} / \mathrm{Si}, \mathrm{Co} / \mathrm{Cu}\end{array}$ & $\mathrm{Cu}, \mathrm{Ni}, \mathrm{Co}$ & [122,163-166] \\
\hline Graphene-like & h-BN & $\begin{array}{c}(\mathrm{ClBNH})_{3}, \mathrm{CH}_{4}, \mathrm{C}_{2} \mathrm{H}_{2} \\
\left(\mathrm{~B}_{3} \mathrm{~N}_{3} \mathrm{H}_{6}\right)\left(\mathrm{B}_{3} \mathrm{~N}_{3} \mathrm{Cl}_{6}\right)\end{array}$ & $\mathrm{Pt}, \mathrm{Si}_{3} \mathrm{~N}_{4} / \mathrm{Si}, \mathrm{Ni}$ & - & [124-126] \\
\hline Materials & $\begin{array}{l}\mathrm{WS}_{2} \\
\mathrm{MoS}_{2}\end{array}$ & $\begin{array}{l}\mathrm{WO}_{3} / \mathrm{S} \\
\mathrm{MoS}_{2} / \mathrm{S}\end{array}$ & $\begin{array}{l}\mathrm{Al}_{2} \mathrm{O}_{3} \\
\mathrm{Si} / \mathrm{SiO}_{2}\end{array}$ & $\begin{array}{l}- \\
-\end{array}$ & $\begin{array}{c}{[126,167]} \\
{[128]}\end{array}$ \\
\hline Carbon $\mathrm{Nc}$ & lotubes & $\begin{array}{c}\mathrm{CH}_{4}, \mathrm{CO} / \mathrm{CH}_{4}, \\
\text { Polypropylene, Acetonitrile, } \\
\text { Aromatic molecules, }\end{array}$ & $\mathrm{Cu}$ & $\begin{array}{l}\mathrm{Ni}, \mathrm{Fe}_{2} \mathrm{O}_{3} / \mathrm{Al}_{2} \mathrm{O}_{3}, \mathrm{Fe} \\
\quad \mathrm{Fe}-\mathrm{Cu}, \mathrm{Pt}-\mathrm{W}\end{array}$ & {$[130-134,154-158,168]$} \\
\hline
\end{tabular}

\section{Simulation of Synthesis Process of Carbon Materials Prepared by CVD}

With the rapid growth of new synthetic materials, the development of low-dimensional nanomaterials with various morphologies has received significant attention. Among the many methods for preparing these nanomaterials, CVD is the most commonly used preparation method due to its simple operation, low cost, diversified product morphology, and high purity rates. However, the CVD method has many influencing factors, compromising control nanomaterial morphology. For nanomaterials, different morphologies have different properties and applications. Therefore, controlling the nanomaterial preparation process is extremely important.

The purpose of the CVD process and reactor simulations is to link the process conditions (gas flow, pressure, and temperature) and reactor structure to the properties of the film [169] (uniformity of film thickness, crystallinity, and chemical composition), as shown in Figure 18. 
Simulations can illustrate the interactions between gas flow, heat and mass transfer, and chemical reactions in order to optimize CVD equipment and processes. Additionally, computational fluid dynamics (CFD) simulations can interpret experimental data and combine specific operating conditions with film properties. Furthermore, for complex physical and chemical changes in CVD reactors, valuable information can be obtained through simulation calculation analysis.

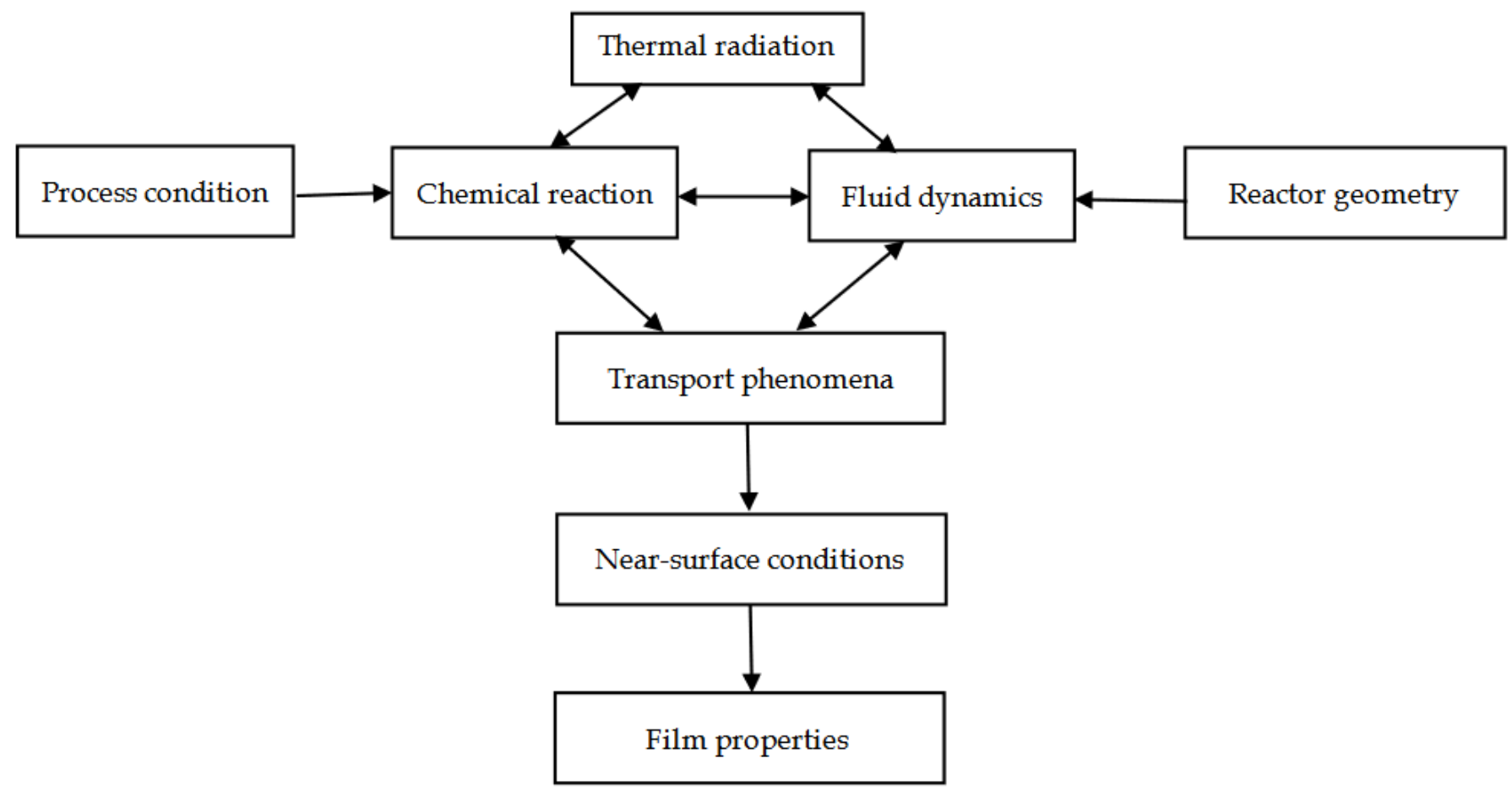

Figure 18. Simulation process [169].

\subsection{Simulation of Synthesis Process of Carbon Fibers Prepared by CVD}

If the experiment is combined with computer simulation, it can not only verify the experimental conjecture, but also optimize the parameters of the existing experiments to achieve production optimization. Misshra and Verma used computational fluid dynamics to simulate the distribution of some reaction parameters of carbon nanofibers in a vertical chemical vapor deposition reactor, such as gas flow velocity, reaction temperature, and concentration release [170], as shown in Figure 19. Their simulation results show that computational fluid dynamics has the potential to optimize process operating conditions and that carbon nanofibers can be grown uniformly on a large scale in a vertical CVD reactor.

At present, the process simulation design of carbon fiber preparation by CVD is minimal. In order to expand the preparation methods and optimal parameters of preparing carbon fiber, computer simulation has become a necessary scientific research tool. 

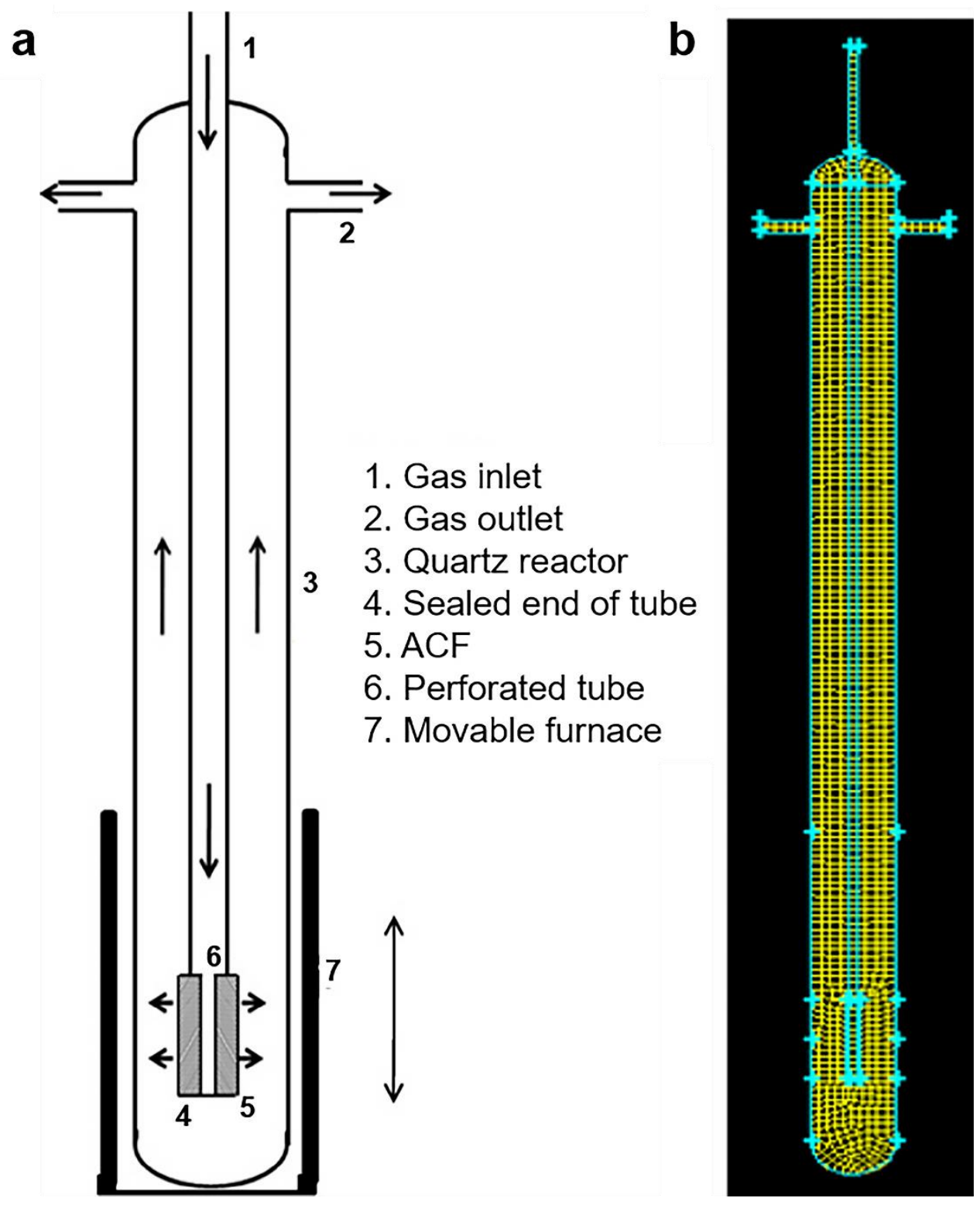

Figure 19. (a) Schematic of CVD reactor. (b) GAMBIT-mesh for simulation [170]. Copyright @ 2021 Elsevier B.V. and the Institution of Chemical Engineers.

\subsection{Simulation of Synthesis Process of Graphene Prepared by CVD}

Chemical vapor deposition is a potential method to produce high-quality and largearea graphene. However, as noted in the previous section, in the chemical vapor deposition system, the precursor, substrate, catalyst, and deposition conditions (temperature, pressure, time, air velocity, etc.) are all parameters affecting the deposition effect. Among them, hydrodynamics is one of the main factors, and computational fluid dynamics (CFD) is adopted. The growth temperature and speed of graphene can be simulated, and the optimal reaction conditions can be optimized or selected according to the simulation results.

Hu et al. reported the relationship between gas flow rate and graphene structure quality and deposition uniformity [171]. The gas flow rate in the CVD furnace under different $\mathrm{Cu}$ substrate structures is simulated by CFD. Through simulation and experimental results, it is concluded that reducing the total gas flow rate can significantly improve the uniform distribution of graphene. Recently, He et al. [172] verified by computational fluid dynamics simulation that graphene films with high crystallinity and high conductivity can be synthesized if copper foil and carbon cloth are used as substrates (Figure 20a). The Brinkman 
equation is applied to describe the flow motion in the porous media. The commercial code COMSOL is used to couple the conservation equations. The quadratic shape function is used for velocity and the linear shape function for pressure and temperature.
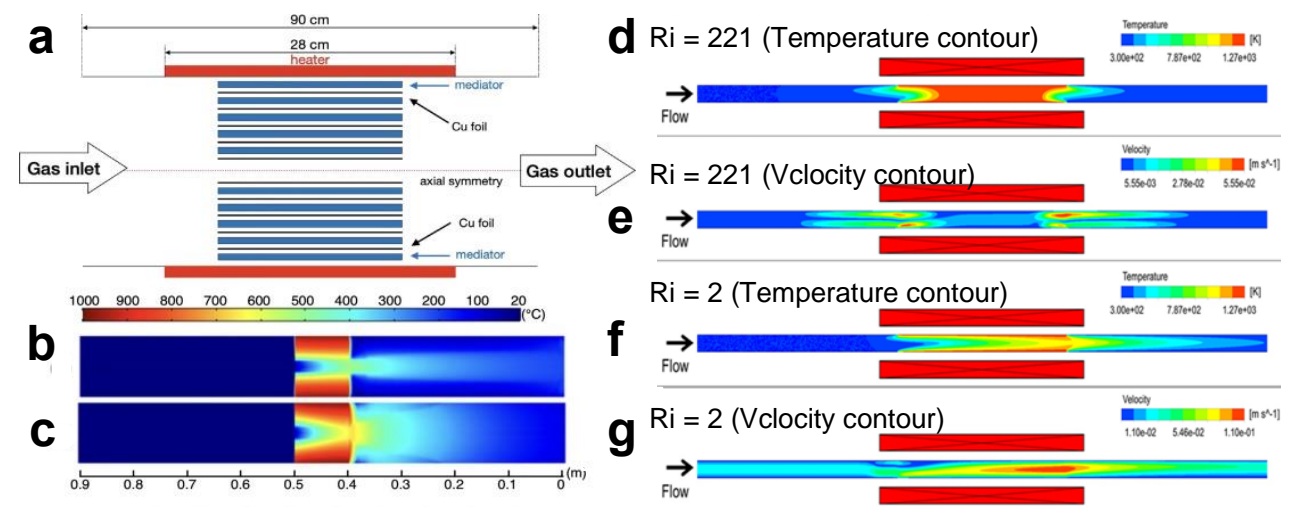

Figure 20. (a) Schematic diagram of CVD system simulation. Temperature distribution for the case of (b) nonporous and (c) 50\% porous mediators [172]. Copyright (C 2021 Elsevier B.V. and Taiwan Institute of Chemical Engineers. Contours of (d) temperature and (e) velocity distribution of Richardson number = 221 (Natural convection); $(\mathbf{f})$ temperature and (g) velocity distribution of Richardson number $=2$ (forced dominant-mixed convection). The furnace (red box) temperature is $1000{ }^{\circ} \mathrm{C}(1273 \mathrm{~K})$ [173].

The conservation of mass, momentum, and energy equations are expressed as: Non-porous medial

$$
\begin{gathered}
\nabla \cdot\left(\rho_{m} \vec{U}\right)=0 \\
\nabla \cdot\left(\rho_{m} \vec{U} \cdot \vec{U}\right)=\nabla \cdot\left[\mu_{m}\left(\nabla \vec{U}+(\nabla \vec{U})^{\mathrm{T}}\right)-\frac{2}{3} \mu_{m}(\nabla \cdot \vec{U}) \mathrm{I}\right]-\nabla \mathrm{P}+\rho_{m} \vec{g}
\end{gathered}
$$

Porous medial

$$
\nabla \cdot\left(\rho_{m} \vec{U} \cdot \vec{U}\right)=\epsilon_{\mathrm{p}} \nabla \cdot\left[\mu_{m}\left(\nabla \vec{U}+(\nabla \vec{U})^{\mathrm{T}}\right)-\frac{2}{3} \mu_{m}(\nabla \cdot \vec{U}) \mathrm{I}\right]-\epsilon_{p}^{2} \nabla P-\epsilon_{p}^{2}\left(\mu \mathcal{K}^{-1}\right) \vec{U}+\epsilon_{p}^{2} \rho_{m} \vec{g}
$$

where $\rho_{m}$ is the density of gas mixture, $\vec{U}$ is the velocity of the mixed gas flow, $\mu_{m}$ is the viscosity of gas mixture, $\mathrm{P}$ is the pressure, $\epsilon_{p}$ is the porosity of mediator, $\kappa$ the permeability of mediator, and $\vec{g}$ is the gravitational acceleration.

Through CFD simulation, we can see the temperature distribution under the conditions of porous and nonporous substrate (Figure 20b,c). The comprehensive study of optimization and multi physical field simulation shows that carbon cloth is an ideal spacer for graphene with high copper loading density. This enhancement is attributed to the uniform cross diffusion of reaction gas / species in the transverse and radial directions, resulting in uniform nucleation and equivalent kinetic growth. In the system, the capacity can reach $15.56 \mathrm{~m}^{2} / \mathrm{h}$. Computational fluid dynamics simulation results show that porous media can improve the gas distribution between copper foils, balance the pressure between copper foils, and promote the high yield synthesis of graphene. It is concluded that under the conditions of a porous substrate, heat energy can pass through the copper foil and porous structure efficiently, which can improve production efficiency. This method provides an effective strategy for the synthesis of high-throughput and large-area deposited graphene films, which is conducive to the low-cost and multi-purpose applications of graphene based materials.

Fauzi et al. studied the influence of hydrodynamics through experimental and numerical methods [173]. In the experiment, two extreme cases of Richardson number with 
strong mixed convection $(R i=2)$ and natural convection $(R i=221)$ are selected (as shown in Figure 20d-g). It can be seen from Figure 20d,e a that when Ri $=221$, the temperature in the heating zone in the furnace is evenly distributed, and the system is greatly affected by buoyancy effect. On the contrary, when $\mathrm{Ri}=2$, the temperature in the heating zone in the furnace is only $900^{\circ} \mathrm{C}$ (Figure 20f), which is less affected by the buoyancy effect, and the flow rate is high (Figure 20g). It is concluded that at higher Reynolds number and lower Richardson number, the gas velocity is not affected by the buoyancy effect because the reflux is very small. At this time, the material residence time is short and the boundary layer is thinner, which can effectively avoid the formation of hydrocarbons and improve the quality of graphene.

In conclusion, porous media can be considered for the selection of substrate, which can improve the gas distribution between copper foils and promote the efficient synthesis of graphene. In the reaction system, attention should also be paid to the Reynolds coefficient. If the coefficient is small and the material residence time is short, high-quality graphene material can be formed. Through simulation, we can more intuitively understand which conditions have higher production efficiency, and even go straight to the depths of the problem to explore the main conditions affecting the reaction to optimize the parameters. For example, the uniform distribution of graphene can be significantly improved by reducing the total gas flow and adjusting the reflux coefficient and the effective heat distribution of porous substrate.

\subsection{Simulation of Synthesis Process of Graphene-like Materials Prepared by CVD}

Due to the excellent properties of graphene-like materials and their great application potential in a wide range of industries, it is a great challenge to explore a low-cost and scalable synthesis of high-quality graphene-like materials. The goal is to combine modern simulation technology with experiment to optimize reaction parameters and obtain the best reaction conditions, so as to prepare a batch of graphene-like materials with high quality and high yield. This will be an important research direction.

Recently, Gao et al. successfully prepared $\mathrm{GeSe}_{2}$ nanofilms on mica substrate by employing chemical vapor deposition techniques [174]. Experimental results show that hydrogen is a key factor in the controlled growth of $\mathrm{GeSe}_{2}$ structure. They also revealed the relationship between sample thickness and distance through CFD simulations. It can be concluded that the closer to the cavity center, the higher the precursor concentration and thus the higher the nucleation density. In order to explore the influence conditions of $\mathrm{MoSe}_{2}$ growth by CVD, Zhou et al. summarized the growth simulation of standard APCVD and flip APCVD to obtain the simulation of evolutionary APCVD [175]. As shown in Figure 21a-d, the gas velocity distribution and shear force distribution, as well as the $\mathrm{MoSe}_{2}$ distribution on the cross section of the matrix and crucible are shown, respectively. By changing the relevant parameters, strengthening the mixing of precursors, reducing the nearby velocity shear rate, and adjusting the flow direction, inch scale monolayer $\mathrm{MoSe}_{2}$ can be successfully prepared.

Kim et al. analyzed the role of hydrogen in the growth of boron nitride nanotubes through thermodynamic equilibrium reaction calculation and numerical analysis of system heat flow [176]. It was found that the velocity amplitude of reverse flow near the wall in the presence of hydrogen is three times higher than that in the absence of hydrogen. When hydrogen is injected, a strong vortex will be generated in the system, making the precursor stay in the system for a long time, which can provide better conditions for the reaction system. The streamlines with arrows as well as the temperature distribution between nucleation and solidification of boron are shown in Figure 21e. Through this method, $12.6 \mathrm{~g}$ BNNTs can be obtained with high yield. 

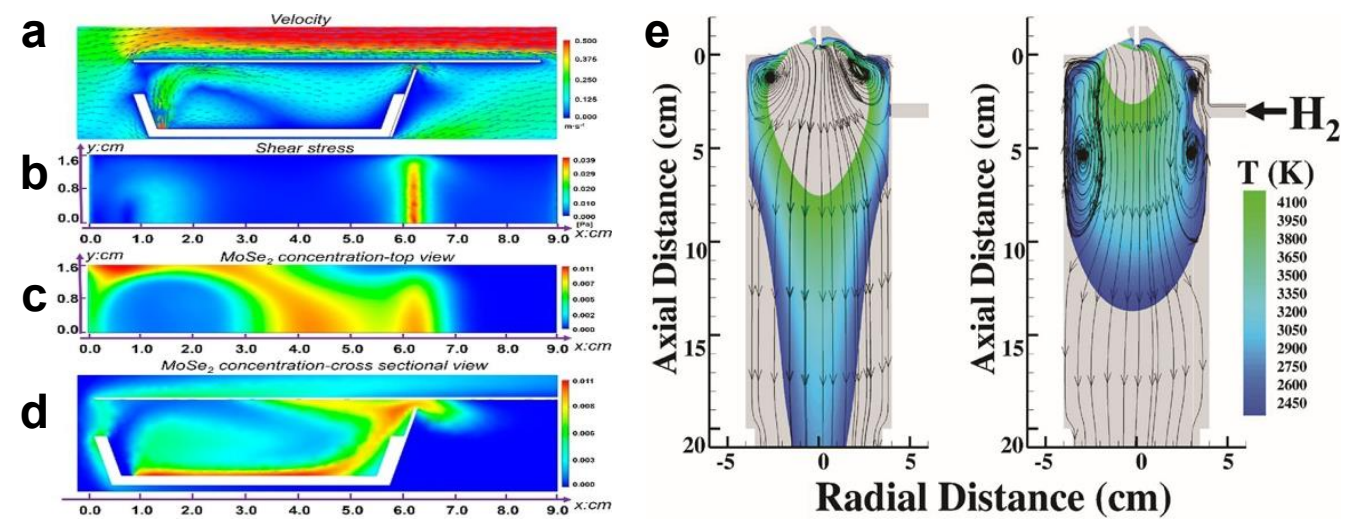

Figure 21. At $t=0.4 \mathrm{~s}$, (a) velocity distribution and velocity vectors and (b) shear stress distribution over the growth substrate. (c) Top-view snapshot of $\mathrm{MoSe}_{2}$ concentration distribution. (d) Crosssection view of $\mathrm{MoSe}_{2}$ concentration. (e) The temperature distribution cut-off between 2300 and $4200 \mathrm{~K}$ as the BNNT growth temperature range (left, without hydrogen; right, with hydrogen).

The preparation of graphene-like materials by CVD is a potential process. Due to the wide variety of graphene-like materials and different conditions, studies will get twice the result with half the effort if computer simulation technology is combined with experiment. The high-quality growth of graphene-like materials is explored through simulation technology, which opens up the market for the application of graphene-like materials.

\subsection{Simulation of Synthesis Process of Carbon Nanotubes Prepared by CVD}

Simulation calculation analysis not only contributes to the improvement and optimization of the CVD reactor design but also explains the reaction mechanisms, including those of low-dimensional nanomaterials. Controllable equipment provides a theoretical basis [177], and CFD simulations can be divided into two main categories: chemical simulations of CVD, and the specific structural designs and its numerical simulations of the CVD reactor.

The goal of the simulation was to illustrate the reaction mechanisms in the gas phase and surface reactions [177-186]. Endo et al. [187] proposed a CFD model that can predict the yield of carbon nanotubes through the catalytic decomposition of xylene in a CVD reactor. This model can predict the velocity and temperature distribution in the reaction zone and can analyze and obtain high-quality preparations. Moraveji et al. [188] studied MWCNT production using fluidized bed catalytic chemical vapor deposition, and a CFD method was used for simulating the hydrodynamics of the reactor and investigating the operational and best velocity for producing high-quality CNTs. These experiments revealed that a temperature of $900{ }^{\circ} \mathrm{C}$, a $\mathrm{CH}_{4}$-to-hydrogen ratio of $1: 4$, and $0.02 \mathrm{~m} / \mathrm{s}$ were the best parameters for MWCNT production using a fluidized bed reactor. The running speed and optimum speed obtained by MFIX simulation of computational fluid dynamics (CFD) program are $0.015 \sim 0.05 \mathrm{~m} / \mathrm{s}$. They also analyzed the porosity distribution in the reactor, as shown in Figure 22. When the flow rate is low, most of the reactants gather in the lower part of the reactor, from where it is difficult to leave the reactor. There are more and more catalytic particles, and the growth quality of carbon nanotubes is better. The simulation results are then applied to experiments with different temperatures and different gas compositions. The experimental results show that $900{ }^{\circ} \mathrm{C}, 1: 4$ methane hydrogen ratio, and $0.02 \mathrm{~m} / \mathrm{s}$ are the best parameters for the production of multi wall nanotubes in a fluidized bed reactor. 


\section{a $V=0.015 \mathrm{~m} / \mathrm{s}$}

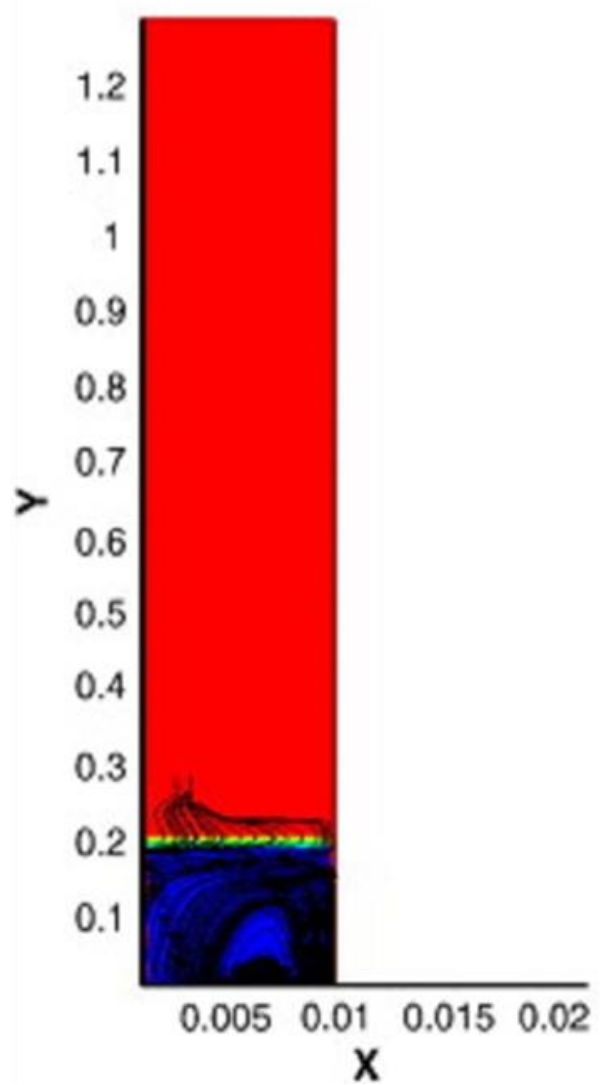

b $\quad V=0.05 \mathrm{~m} / \mathrm{s}$

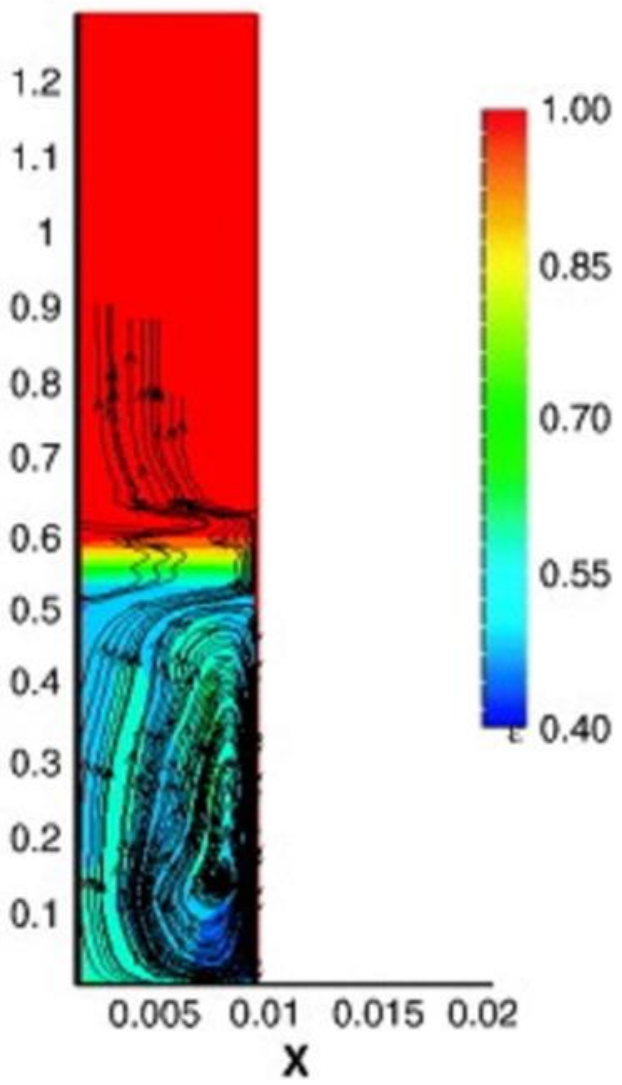

Figure 22. Void fraction distribution in the length of the reactor. The running speed and optimum speed are (a) $\mathrm{V}=0.015 \mathrm{~m} / \mathrm{s}$ and $(\mathbf{b}) \mathrm{V}=0.05 \mathrm{~m} / \mathrm{s}$ [188].

Seo et al. [189] used CFD to improve the uniformity of silicon carbide chemical vapor deposition and demonstrated that commercial CFD software can handle the entire reaction. Specifically, FactSage 6.2 and COMSOL 4.4 were used to predict the thermodynamic phases and deposition phenomena for $\mathrm{SiC}$ deposition, respectively. According to the simulation results, the process parameters were determined to optimize the growth conditions of a more uniform and effective $\mathrm{SiC}$ coating in the $\mathrm{CH}_{3} \mathrm{SiCl}_{3}$ (MTS) and hydrogen systems. $\mathrm{CFD}$ was then used to predict the growth rate of the film, and the prediction results were applied to the optimization of the film growth parameters to obtain a more uniform film thickness and a higher film growth rate. The correlation between the CFD model and the experimental results demonstrates the potential of CFD simulation in improving deposition conditions and optimizing hardware for better yields. A newly developed pulse plasma CVD method was used to successfully grow SWNTs with narrow chirality distributions at a relatively high yield, which was facilitated by improved control of SWNT incubation dynamics [190].

The simulation done by Kleijn and Hoogendoorn [191] and Kim et al. [192] mainly considered the fluid flow and transmission phenomenon inside the reactor under different process and operating conditions and reactor structures, while ignoring the chemical reactions in the CVD process.

Min and Jiang [193] used CFD to simulate CNT synthesis by using a nozzle-type CVD reactor model. The numerical simulation reactor shown in Figure 23 consists of a quartz tube, a furnace, and a quartz platform. The quartz platform is placed in the quartz tube to provide a substrate for the growth of carbon nanotubes. The quartz tube is divided into two parts-the preheating furnace and the reaction furnace. Xylene evaporates in the first furnace and then enters into the second furnace. The corresponding chemical reaction is 
carried out in the second part, and the deposited carbon forms carbon nanotubes on the quartz platform. The model utilized the conservation equations for mass, momentum, and heat, and the mass fractions of the reactant, product species, and chemical reactions. Based on this model, the study simulated product distribution and the rate of the carbon deposition velocity distribution in a nozzle-type CVD reactor and CVD reactor without a nozzle and compared the carbon deposition variation rate of the nozzle-type CVD reaction at different temperatures. The simulation results showed that the nozzle-type CVD reactor was more efficient than the CVD reactor without a nozzle. Moreover, at 873, 923, 973, 993, and $1023 \mathrm{~K}$, the carbon deposition rate increased as temperature increased.

\section{a}

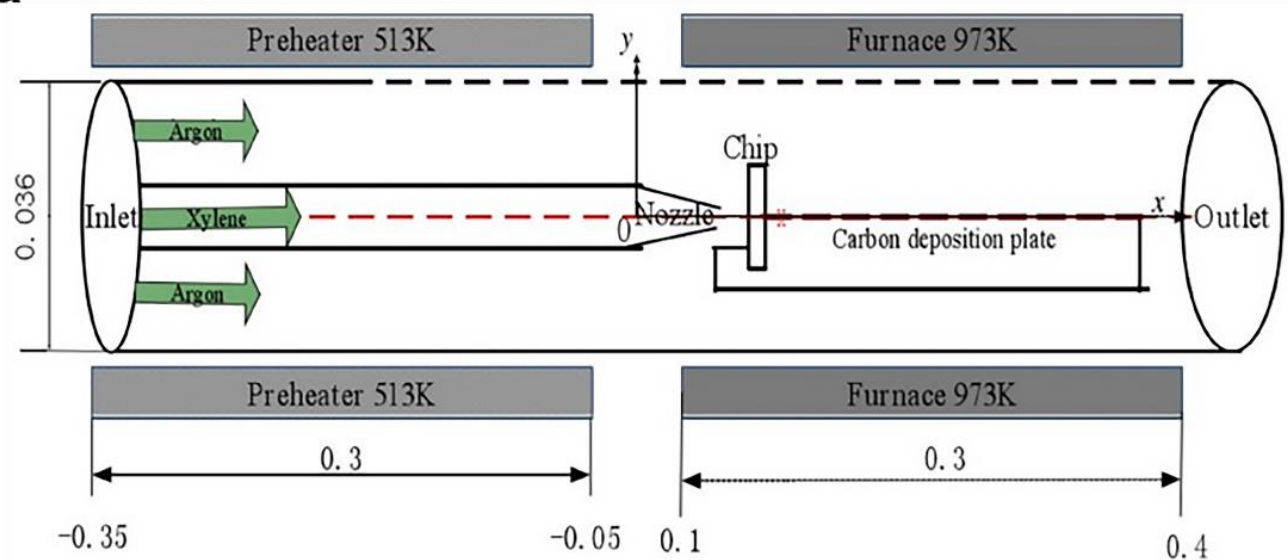

b

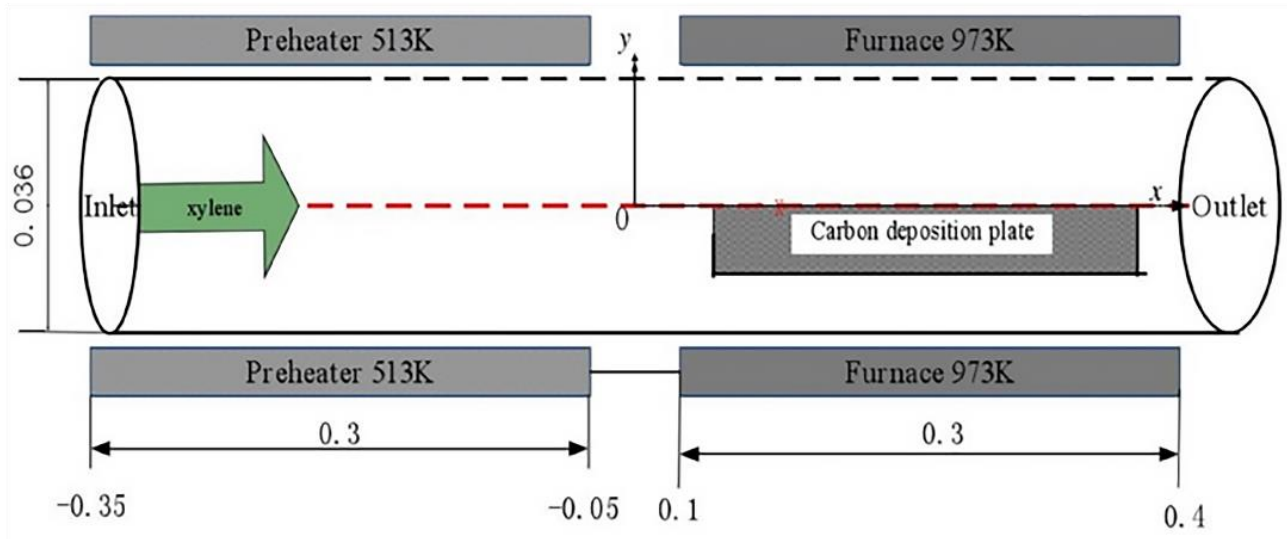

Figure 23. Schematics of chemical vapor deposition (CVD) reactor with nozzle (a) and CVD reactor without a nozzle (b) [193].

The carbon deposition rate distribution curves of the four reactors with different structures were compared under the same external conditions, as well as the deposition rate curves of the four structures. The four structures are: (I) without nozzle and chip structure; (II) nozzle and chip structure; (III) with nozzle and without chip structure; and (IV) with baffle and without chip structure. The results confirmed that the composition of the internal structure of the nozzle-type CVD reactor was beneficial in promoting increased carbon deposition (Figure 24). 
a

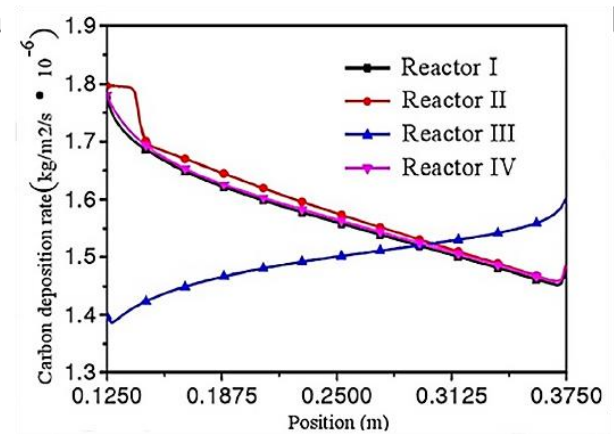

b

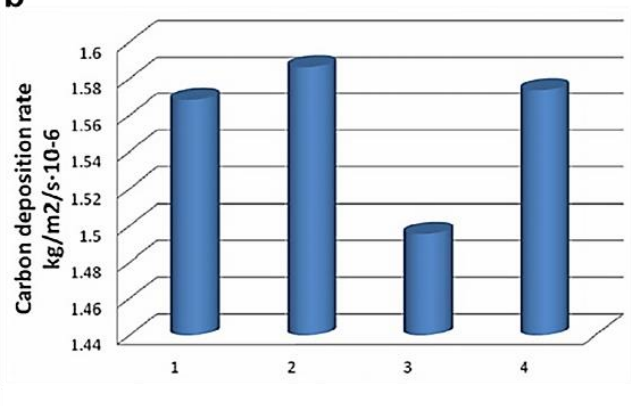

Figure 24. (a) Carbon deposition rates in four different structural reactors; (b) average carbon deposition rates in four different reactors [193].

Zhao et al. [194] also performed modeling to predict the effects of process parameters on carbon nanotube growth by CVD at ambient pressure using a simplified 2D geometry model. Acetylene was the precursor and argon was the diluent. The whole process was carried out at atmospheric pressure, and the precursor of the catalyst was the pure cobalt nitrate crystal $\left(\mathrm{CO}\left(\mathrm{NO}_{3}\right)_{2} \cdot 6 \mathrm{H}_{2} \mathrm{O}\right)$. The simulation used finite element methods and described the temperature, concentration, and velocity fields. The temperature field in the furnace region was simulated, and the positioning of the temperature field surface plot was presented and discussed. The results indicated that there was a steep thermal gradient in the furnace along the axial direction during the CVD process. However, there were equal temperature and concentration fields in the high-temperature region that were suitable for the growth of CNTs. When the volume ratio of acetylene to argon is 1:5, a large amount of carbon black and pyrolytic carbon are generated in the sediment. When the volume ratio of acetylene to argon is 1:10, carbon nanotubes with high purity can be obtained. Thus, the model was accurate enough to provide a guide for process optimization and assisted in detailing the principles of CVD processes for CNTs. The computer model was suitable for analyzing and studying the CVD process for the manufacturing of CNTs.

Xu's team also used the CFD pre-processing software Gambit to build two twodimensional models of gas flow field in the vertical carbon nanotube fiber reactor, which consisted of a straight inlet pipe model and a horn-shaped inlet pipe model, with a network that was divided to meet the simulation requirements [195]. Thus, a mathematical model of the gas flow field was established. Second, the flow field was numerically simulated using FLUENT calculation software, and the gas velocity field and temperature field distribution in the two reactors were obtained. Subsequently, the differential influence of the two different inlet pipe structures on the flow field was analyzed. Finally, the effects of the geometric parameters of the reactor on the flow field were assessed. A cylindrical inner sleeve was added inside the reactor, and gas property changes with temperature were incorporated into the model. The three geometries of the reactor were then studied using the controlled variable method. These analyses revealed a reflux zone near the outlet of the inner sleeve, which was consistent with the observed rising smoke, possibly explaining the phenomenon in which nanotubes tend to accumulate in the center of a reactor.

Recently, some CFD commercial software programs with CVD modules have improved, such as FLUENT, CFD-ACE, and CFX. These programs can simulate typical CVD phenomena, such as multi-component gas phase diffusion, heat conduction, and complex multi-component reactions, as well as gas phases and surface chemistry. Development of commercial software has further promoted simulation of the CFD process and equipment. CFD simulation is thus an auxiliary means for reactor design and process optimization, as well as a tool for rational interpretation of experimental data. Therefore, CFD simulation can be successfully used for design and optimization, providing a favorable method for computer-aided advanced CVD deposition [196-198].

It is found that high quality multi walled carbon nanotubes can be prepared when the hydrocarbon ratio is 1:4. When the precursor is acetylene, carbon nanotubes with high 
purity can be obtained when the volume ratio of acetylene to argon is 1:10. The nozzle furnace is conducive to more carbon deposition.

Table 3 lists the simulation results of some preparation processes. After the optimized parameters are obtained through the simulation, it can not only improve the quality of the product, but also improve the yield and growth size of the product, so as to provide theoretical support for the preparation of high-performance and large-scale products.

Table 3. Optimization of carbon nanomaterials properties and synthesis parameters by using computer simulations.

\begin{tabular}{|c|c|c|c|c|c|}
\hline Materials & Results & $\begin{array}{c}\text { Production } \\
\text { Quantity }\end{array}$ & Growth Velocity & Size & Ref. \\
\hline \multicolumn{2}{|c|}{ Carbon fiber } & - & $\begin{array}{l}5 \times 10^{-13} \\
\mathrm{~kg} / \mathrm{m}^{2} \cdot \mathrm{s}\end{array}$ & a large scale & [170] \\
\hline \multirow{2}{*}{\multicolumn{2}{|c|}{ Graphene }} & - & $\begin{array}{c}9.33 \mathrm{~m}^{2} / \mathrm{h}-17.88 \\
\mathrm{~m}^{2} / \mathrm{h}\end{array}$ & 6-8 inch & [172] \\
\hline & & - & $\begin{array}{c}1.04 \times 10^{-7} \mathrm{~kg} \\
\mathrm{~m}^{-2} \cdot \mathrm{s}^{-1}\end{array}$ & - & [199] \\
\hline \multirow{4}{*}{$\begin{array}{l}\text { Graphene-like } \\
\text { Materials }\end{array}$} & & - & $1.5 \mu \mathrm{m} \cdot \mathrm{s}^{-1}$ & - & [200] \\
\hline & $\mathrm{GeSe}_{2}$ & - & - & large-scale & [104] \\
\hline & $\mathrm{MoSe}_{2}$ & . & - & inch-scale & [175] \\
\hline & $\mathrm{h}-\mathrm{BN}$ & $12.6 \mathrm{~g}$ & - & $\sim 7 \mathrm{~nm}$ & [176] \\
\hline \multirow{2}{*}{\multicolumn{2}{|c|}{ Carbon nanotube }} & $350 \mathrm{mg} \mathrm{h}^{-1}$ & - & - & [187] \\
\hline & & & $0.015 \sim 0.05 \mathrm{~m} / \mathrm{s}$ & $\sim 188 \mu \mathrm{m}$ & [188] \\
\hline
\end{tabular}

\section{Summary and Future Directions}

This paper summarizes the structure, properties, preparation, and modern computing technology of carbon materials- the application of computational fluid dynamics simulation in the preparation of materials. There are many kinds of carbon nano-materials and their structures have their own characteristics, and different structures will lead to special properties and affect the application field of the material. A major factor affecting the material structure is its preparation link. Different preparation methods and different conditions will have a great impact on the structure and properties of the material. This paper mainly introduces the preparation of carbon materials and graphene-like materials by CVD and the simulation of CVD system. The following is a summary:

1. The structural defects or doping of materials will have a certain impact on the properties of materials. The structure can be adjusted through the selection of preparation methods and the adjustment of process conditions to improve or inhibit some properties.

2. In addition to the selection of conventional precursors, substrate materials and catalysts, the reaction temperature, time, pressure, and atmosphere have an impact on the growth quality, yield, and growth size of the materials. Only by grasping the choice of precursor and other materials and controlling the process conditions can we obtain higher quality and high performance carbon materials.

3. Numerical simulation and analysis can provide valuable information for the complex physical and chemical changes in a chemical vapor deposition reactor. In the process of computational fluid dynamics simulation, the reaction parameters and reactor design can be optimized, and the temperature and velocity distribution of the reaction system can be simulated. Through the combination of simulation calculation and experiment, the improvement of production efficiency and production scale can be obtained.

With the rapid development of carbon nano-materials, demand for them is only increasing. Therefore, for the wide application of carbon nano-materials, the preparation process needs to keep pace to achieve high efficiency and high quality. The rapid development of computer technology undoubtedly contributes to the development of carbon nano-materials. Combining computer simulation with theory or experiment can optimize 
the existing preparation process; at the same time, it can verify reasonable guesses and realize the perfect combination of thinking and doing.

The development and study of carbon nano-materials with various morphologies has received significant attention, especially due to the urgent need for new synthetic materials. Presently, due to technical reasons, carbon nano-materials cannot be routinely used in industrial production due to difficulties in producing continuous high-quality carbon nano-materials in batches. Furthermore, the structure of the prepared carbon nanotubes cannot be arbitrarily controlled, as too many factors influence carbon nanotube quality and yield [201,202]. Among the various methods for preparing CNTs, the CVD method has attracted attention due to its simple operation, low cost, diversified morphology, and resulting high purity of the prepared CNTs. However, there are many experimental conditions for CVD, making it difficult to control the morphology of the CNTs. Thus, researchers have adjusted the morphology of CNTs by changing various experimental conditions to correlate experimental conditions with morphology, in order to better produce carbon nanotubes with the desired morphologies and properties. However, experiments cannot solely explain the effects of the local reactions on the reaction process. Combining computational analysis with experimental research provides a better method for determining the influence of various experimental conditions on the morphology of carbon nano-materials during the growth process. This allows the optimization of various process parameters, improving the reactor and preparing controllable high-quality carbon nano-materials. As a result, more in-depth research on carbon nano-materials will be important in the future-the reaction process and parameters are optimized by computer simulation technology, and the growth and structural changes of materials are regulated in combination with experiments, so as to achieve the purpose of application in different fields.

Author Contributions: Writing—original draft preparation, B.Y. and L.G.; methodology, M.X.; software, H.W. (Haihe Wang); validation, Y.H., Y.L. and H.X.; formal analysis, H.H.; investigation, C.C.; resources, H.W. (Huanjiang Wang); data curation, J.Z.; visualization, Y.-F.L.; supervision, G.X.; project administration, X.T.; funding acquisition and writing—review and editing, Y.X.; All authors have read and agreed to the published version of the manuscript.

Funding: This work was financially supported by the National Natural Science Foundation of China (No. 52062005 and No.52074141), key Science and Technology Support Project of Guizhou Province(No.[2021]326), the Science and Technology Foundation of Guizhou Province, China ([2018] 1173, [2020]1Y163), the National Natural Science Foundation of China (Nos. 21861012), the Natural Science Foundation of Guizhou Education Commission (Nos. 2018148), Guizhou Science \& Technology Commission (Nos. 20201Z005,20191157), Science and Technology Foundation of Guizhou Province, China ([2019]1158 and ZK[2021] Common 051 and Guizhou provincial teaching project [ky 2018] 016.

Institutional Review Board Statement: Not applicable.

Informed Consent Statement: Informed consent was obtained from all subjects involved in the study.

Data Availability Statement: Data sharing not applicable. No new data were created or analyzed in this study. Data sharing is not applicable to this article.

Conflicts of Interest: The authors declare no conflict of interest.

\section{References}

1. Wang, G.; Yu, M.; Feng, X. Carbon materials for ion-intercalation involved rechargeable battery technologies. Chem. Soc. Rev. 2021, 50, 2388-2443. [CrossRef]

2. Fitzer, E. Pan-based carbon fibers-present state and trend of the technology from the viewpoint of possibilities and limits to influence and to control the fiber properties by the process parameters. Carbon 1989, 27, 621-645. [CrossRef]

3. Edie, D. The effect of processing on the structure and properties of carbon fibers. Carbon 1998, 36, 345-362. [CrossRef]

4. Huang, X. Fabrication and Properties of Carbon Fibers. Materials 2009, 2, 2369-2403. [CrossRef]

5. Liu, Y.; Kumar, S. Recent Progress in Fabrication, Structure, and Properties of Carbon Fibers. Polym. Rev. 2012, 52, $234-258$. [CrossRef] 
6. Li, W.; Long, D.; Miyawaki, J.; Qiao, W.; Ling, L.; Mochida, I.; Yoon, S.-H. Structural features of polyacrylonitrile-based carbon fibers. J. Mater. Sci. 2011, 47, 919-928. [CrossRef]

7. Meek, N.; Penumadu, D. Nonlinear elastic response of pan based carbon fiber to tensile loading and relations to microstructure. Carbon 2021, 178, 133-143. [CrossRef]

8. Novoselov, K.S.; Geim, A.K.; Morozov, S.V.; Jiang, D.; Zhang, Y.; Dubonos, S.V.; Grigorieva, I.V.; Firsov, A.A. Electric Field Effect in Atomically Thin Carbon Films. Science 2004, 306, 666-669. [CrossRef]

9. Novoselov, K.S.; Fal'ko, V.I.; Colombo, L.; Gellert, P.R.; Schwab, M.G.; Kim, K. A roadmap for graphene. Nature 2012, 490, 192-200. [CrossRef]

10. Peigney, A.; Laurent, C.; Flahaut, E.; Bacsa, R.; Rousset, A. Specific surface area of carbon nanotubes and bundles of carbon nanotubes. Carbon 2001, 39, 507-514. [CrossRef]

11. Gadipelli, S.; Guo, Z.X. Graphene-based materials: Synthesis and gas sorption, storage and separation. Prog. Mater. Sci. 2015, 69, 1-60. [CrossRef]

12. Cao, Y.; Fatemi, V.; Fang, S.; Watanabe, K.; Taniguchi, T.; Kaxiras, E.; Jarillo-Herrero, P. Unconventional superconductivity in magic-angle graphene superlattices. Nature 2018, 556, 43-50. [CrossRef]

13. Kumar, N.; Salehiyan, R.; Chauke, V.; Botlhoko, O.J.; Setshedi, K.; Scriba, M.; Masukume, M.; Ray, S.S. Top-down synthesis of graphene: A comprehensive review. FlatChem 2021, 27, 100224. [CrossRef]

14. Alam Bhuyan, S.; Uddin, N.; Islam, M.; Alam Bipasha, F.; Hossain, S.S. Synthesis of graphene. Int. Nano Lett. 2016, 6, 65-83. [CrossRef]

15. Geim, A.K.; Novoselov, K. The rise of graphene. Nat. Mater. 2007, 6, 183-191. [CrossRef]

16. Mao, H.Y.; Laurent, S.; Chen, W.; Akhavan, O.; Imani, M.; Ashkarran, A.A.; Mahmoudi, M. Graphene: Promises, Facts, Opportunities, and Challenges in Nanomedicine. Chem. Rev. 2013, 113, 3407-3424. [CrossRef]

17. Zheng, X.T.; Ananthanarayanan, A.; Luo, K.Q.; Chen, P. Glowing Graphene Quantum Dots and Carbon Dots: Properties, Syntheses, and Biological Applications. Small 2015, 11, 1620-1636. [CrossRef]

18. Peng, J.; Gao, W.; Gupta, B.K.; Liu, Z.; Romero-Aburto, R.; Ge, L.; Song, L.; Alemany, L.B.; Zhan, X.; Gao, G.; et al. Graphene Quantum Dots Derived from Carbon Fibers. Nano Lett. 2012, 12, 844-849. [CrossRef]

19. Cheng, C.; Li, S.; Thomas, A.; Kotov, N.A.; Haag, R. Functional Graphene Nanomaterials Based Architectures: Biointeractions, Fabrications, and Emerging Biological Applications. Chem. Rev. 2017, 117, 1826-1914. [CrossRef]

20. Wilson, J.A.; Yoffe, A.D. The transition metal dichalcogenides discussion and interpretation of the observed optical, electrical and structural properties. Adv. Phys. 2006, 18, 193. [CrossRef]

21. Osada, M.; Sasaki, T. Two-Dimensional Dielectric Nanosheets: Novel Nanoelectronics from Nanocrystal Building Blocks. Adv. Mater. 2012, 24, 210. [CrossRef]

22. Hozoi, L.; Siurakshina, L.; Fulde, P.; Brink, J.V.D. Ab Initio determination of Cu 3d orbital energies in layered copper oxides. Sci. Rep. 2011, 1, 65. [CrossRef]

23. Golberg, D.; Bando, Y.; Huang, Y.; Terao, T.; Mitome, M.; Tang, C.; Zhi, C. Boron Nitride Nanotubes and Nanosheets. ACS Nano 2010, 4, 2979. [CrossRef]

24. Zhang, H.; Liu, C.-X.; Qi, X.-L.; Dai, X.; Fang, Z.; Zhang, S.-C. Topological insulators in Bi2Se3, Bi2Te3 and Sb2Te3 with a single Dirac cone on the surface. Nat. Phys. 2009, 5, 438-442. [CrossRef]

25. Tang, H.; Liang, D.; Qiu, R.L.J.; Gao, X.P.A. Two-Dimensional Transport-Induced Linear Magneto-Resistance in Topological Insulator Bi2Se3 Nanoribbons. ACS Nano 2011, 5, 7510-7516. [CrossRef]

26. Dean, C.R.; Young, A.; Meric, I.; Lee, C.; Wang, L.; Sorgenfrei, S.; Watanabe, K.; Taniguchi, T.; Kim, P.; Shepard, K.L.; et al. Boron nitride substrates for high-quality graphene electronics. Nat. Nanotechnol. 2010, 5, 722-726. [CrossRef]

27. Radisavljevic, B.; Whitwick, M.B.; Kis, A. Integrated Circuits and Logic Operations Based on Single-Layer MoS. ACS Nano 2011, 5, 9934-9938. [CrossRef]

28. Mak, K.F.; Lee, C.; Hone, J.; Shan, J.; Heinz, T.F. Atomically ThinMoS2: A New Direct-Gap Semiconductor. Phys. Rev. Lett. 2010, 105, 136805. [CrossRef]

29. Rokuta, E.; Hasegawa, Y.; Suzuki, K.; Gamou, Y.; Oshima, C.; Nagashima, A. Phonon Dispersion of an Epitaxial Monolayer Film of Hexagonal Boron Nitride on Ni(111). Phys. Rev. Lett. 1997, 79, 4609-4612. [CrossRef]

30. Radisavljevic, B.; Radenovic, A.; Brivio, J.; Giacometti, V.; Kis, A. Single-layer MoS2 transistors. Nat. Nanotechnol. 2011, 6, 147-150. [CrossRef]

31. Pawar, R.; Sangolkar, A.A. Density functional theory studies on h-BN-transition metal dichalcogenide heterostructures (TMDCs) and TMDC-h-BN-TMDC (sandwich heterostructures). Comput. Theor. Chem. 2021, 1204, 113417. [CrossRef]

32. Pan, H.; Yin, X.; Xue, J.; Cheng, L.; Zhang, L. The microstructures, growth mechanisms and properties of carbon nanowires and nanotubes fabricated at different CVD temperatures. Diam. Relat. Mater. 2017, 72, 77-86. [CrossRef]

33. Zhang, R.; Zhang, Y.; Wei, F. Horizontally aligned carbon nanotube arrays: Growth mechanism, controlled synthesis, characterization, properties and applications. Chem. Soc. Rev. 2017, 46, 3661-3715. [CrossRef]

34. Oberlin, A.; Endo, M.; Koyama, T. Filamentous growth of carbon through benzene decomposition. J. Cryst. Growth 1976, 32, 335-349. [CrossRef]

35. Iijima, S.; Ichihashi, T. Single-shell carbon nanotubes of 1-nm diameter. Nature 1993, 363, 603-605. [CrossRef] 
36. Bocko, J.; Lengvarský, P.; Huňady, R.; Šarloši, J. The computation of bending eigenfrequencies of single-walled carbon nanotubes based on the nonlocal theory. Mech. Sci. 2018, 9, 349-358. [CrossRef]

37. Iijima, S. Helical microtubules of graphitic carbon. Nature 1991, 354, 56-58. [CrossRef]

38. Thostenson, E.T.; Ren, Z.; Chou, T.-W. Advances in the science and technology of carbon nanotubes and their composites: A review. Compos. Sci. Technol. 2001, 61, 1899-1912. [CrossRef]

39. Su, D.S. 20 Years of Carbon Nanotubes. ChemSusChem 2011, 4, 811-813. [CrossRef]

40. Eatemadi, A.; Daraee, H.; Karimkhanloo, H.; Kouhi, M.; Zarghami, N.; Akbarzadeh, A.; Abasi, M.; Hanifehpour, Y.; Joo, S.W. Carbon nanotubes: Properties, synthesis, purification, and medical applications. Nanoscale Res. Lett. 2014, 9, 393. [CrossRef]

41. Rinzler, A.G.; Liu, J.; Dai, H.; Nikolaev, P.; Huffman, C.B.; Rodriguez-Macias, F.; Boul, P.J.; Lu, A.H.; Heymann, D.; Colbert, D.T.; et al. Large-scale purification of single-wall carbon nanotubes: Process, product, and characterization. Appl. Phys. A 1998, 67, 29-37. [CrossRef]

42. Gu, Z.; Peng, H.; Hauge, R.H.; Smalley, R.E.; Margrave, J.L. Cutting Single-Wall Carbon Nanotubes through Fluorination. Nano Lett. 2002, 2, 1009-1013. [CrossRef]

43. Popov, V. Carbon nanotubes: Properties and application. Mater. Sci. Eng. R Rep. 2004, 43, 61-102. [CrossRef]

44. Baughman, R.H.; Zakhidov, A.A.; de Heer, W.A. Carbon Nanotubes-the Route Toward Applications. Science 2002, $297,787-792$. [CrossRef]

45. Terrones, M. Science and Technology of the Twenty-First Century: Synthesis, Properties, and Applications of Carbon Nanotubes. Annu. Rev. Mater. Res. 2003, 33, 419-501. [CrossRef]

46. Dai, H.; Wong, E.W.; Lu, Y.Z.; Fan, S.; Lieber, C.M. Synthesis and characterization of carbide nanorods. Nature 1995, 375, 769-772. [CrossRef]

47. De Heer, W.A. Nanotubes and the Pursuit of Applications. MRS Bull. 2004, 29, 281-285. [CrossRef]

48. Han, W.; Fan, S.; Li, Q.; Hu, Y. Synthesis of Gallium Nitride Nanorods Through a Carbon Nanotube-Confined Reaction. Science 1997, 277, 1287-1289. [CrossRef]

49. Zhang, X.; Lu, W.; Zhou, G.; Li, Q. Understanding the Mechanical and Conductive Properties of Carbon Nanotube Fibers for Smart Electronics. Adv. Mater. 2020, 32, e1902028. [CrossRef]

50. Wang, S.; Wang, W.; Li, J.; Ni, Z. Chemical Vapor Deposition Growth of Large-Areas Two-Dimensional Materials Approaches and Mechanisms. Acta Phys. Sin. 2021, 70, 026802. (In Chinese) [CrossRef]

51. Oncel, C.; Yürüm, Y. Carbon Nanotube Synthesis via the Catalytic CVD Method: A Review on the Effect of Reaction Parameters. Full-Nanotub. Carbon Nanostruct. 2006, 14, 17-37. [CrossRef]

52. Kumar, S.; Anderson, D.P.; Crasto, A.S. Carbon fibre compressive strength and its dependence on structure and morphology. J. Mater. Sci. 1993, 28, 423-439. [CrossRef]

53. Huang, Y.; Young, R. Effect of fibre microstructure upon the modulus of PAN- and pitch-based carbon fibres. Carbon 1995, 33, 97-107. [CrossRef]

54. Hunt, M.A.; Saito, T.; Brown, R.H.; Kumbhar, A.S.; Naskar, A.K. Patterned Functional Carbon Fibers from Polyethylene. Adv. Mater. 2012, 24, 2386-2389. [CrossRef]

55. McCann, E. Electronic Properties of Monolayer and Bilayer Graphene. Graphene Nanoelectronics; Springer: Berlin/Heidelberg, Germany, 2011; pp. 237-275.

56. Monteiro, J.; Frota, H. Graphene on a hexagonal lattice substrate with on-site Hubbard interaction. Solid State Commun. 2021, 328, 114250. [CrossRef]

57. Geng, D.; Yang, S.; Zhang, Y.; Yang, J.; Liu, J.; Li, R.; Sham, T.-K.; Sun, X.; Ye, S.; Knights, S. Nitrogen doping effects on the structure of graphene. Appl. Surf. Sci. 2011, 257, 9193-9198. [CrossRef]

58. Yang, G.; Li, L.; Lee, W.B.; Cheung, N.M. Structure of graphene and its disorders: A review. Sci. Technol. Adv. Mater. 2018, 19, 613-648. [CrossRef]

59. Rao, C.N.R.; Biswas, K.; Subrahmanyam, K.S.; Govindaraj, A. Graphene, the new nanocarbon. J. Mater. Chem. 2009, 19, 2457-2469. [CrossRef]

60. Kubota, Y.; Watanabe, K.; Tsuda, O.; Taniguchi, T. Deep Ultraviolet Light-Emitting Hexagonal Boron Nitride Synthesized at Atmospheric Pressure. Science 2007, 317, 932-934. [CrossRef]

61. Xu, M.; Liang, T.; Shi, M.; Chen, H. Graphene-Like Two-Dimensional Materials. Chem. Rev. 2013, 113, 3766-3798. [CrossRef]

62. Makinistian, L.; Albanesi, E. Ab initiocalculations of the electronic and optical properties of germanium selenide. J. Phys. Condens. Matter 2007, 19, 186211. [CrossRef] [PubMed]

63. Chang, H.; In, E.; Kong, K.-J.; Lee, J.-O.; Choi, Y.; Ryu, B.-H. First-Principles Studies of SnS2 Nanotubes: A Potential Semiconductor Nanowire. J. Phys. Chem. B 2005, 109, 30-32. [CrossRef]

64. Errico, L.A. Ab initio FP-LAPW study of the semiconductors $\mathrm{SnO}$ and $\mathrm{SnO}_{2}$. Phys. B Condens. Matter 2007, 389, 140-144. [CrossRef]

65. Zhang, X.; Shen, J.; Lin, S.; Li, J.; Chen, Z.; Li, W.; Pei, Y. Thermoelectric properties of GeSe. J. Mater. 2016, 2, 331-337. [CrossRef]

66. Cui, H.; Jia, P.; Peng, X.; Li, P. Adsorption and sensing of CO and C2H2 by S-defected SnS2 monolayer for DGA in transformer oil: A DFT study. Mater. Chem. Phys. 2020, 249, 123006. [CrossRef]

67. Ajayan, P.M.; Ebbesen, T.W. Nanometre-size tubes of carbon. Rep. Prog. Phys. 1997, 60, 1025-1062. [CrossRef] 
68. Sinnott, S.; Shenderova, O.; White, C.; Brenner, D. Mechanical properties of nanotubule fibers and composites determined from theoretical calculations and simulations. Carbon 1998, 36, 1-9. [CrossRef]

69. Yang, K.; He, J.; Su, Z.; Reppert, J.B.; Skove, M.J.; Tritt, T.M.; Rao, A.M. Inter-tube bonding, graphene formation and anisotropic transport properties in spark plasma sintered multi-wall carbon nanotube arrays. Carbon 2010, 48, 756-762. [CrossRef]

70. Lu, J. Elastic Properties of Carbon Nanotubes and Nanoropes. Phys. Rev. Lett. 1997, 79, 1297-1300. [CrossRef]

71. Manoharan, M.P.; Sharma, A.; Desai, A.V.; Haque, M.; Bakis, C.; Wang, K.W. The interfacial strength of carbon nanofiber epoxy composite using single fiber pullout experiments. Nanotechnology 2009, 20, 295701. [CrossRef] [PubMed]

72. Kasumov, A.Y.; Deblock, R.; Kociak, M.; Reulet, B.; Bouchiat, H.; Khodos, I.I.; Gorbatov, Y.B.; Volkov, V.T.; Journet, C.; Burghard, M. Supercurrents Through Single-Walled Carbon Nanotubes. Science 1999, 284, 1508-1511. [CrossRef]

73. Bonard, J.-M.; Stöckli, T.; Maier, F.; de Heer, W.A.; Châtelain, A.; Salvetat, J.-P.; Forró, L. Field-Emission-Induced Luminescence from Carbon Nanotubes. Phys. Rev. Lett. 1998, 81, 1441-1444. [CrossRef]

74. Wang, Q.; Dai, J.; Li, W.; Wei, Z.; Jiang, J. The effects of CNT alignment on electrical conductivity and mechanical properties of SWNT/epoxy nanocomposites. Compos. Sci. Technol. 2008, 68, 1644-1648. [CrossRef]

75. Hu, H.; Gong, Y.; Peng, X.; Yin, H. An anisotropic hyperelastic constitutive model considering shear-tension coupling for 2-dimensional woven fabrics. Acta Mater. Composit. Sin. 2017, 34, 1388-1393. (In Chinese) [CrossRef]

76. Li, C.; Dong, H. Effect of aligned multiwalled carbon nanotubes induced by electric field on properties of multiwalled carbon nanotubes/epoxy resin composites. Acta Mater. Composit. Sin. 2018, 35, 2387-2396. (In Chinese) [CrossRef]

77. Johnson, D.J. Structure-property relationships in carbon fibres. J. Phys. D Appl. Phys. 1987, 20, 286-291. [CrossRef]

78. Li, D.; Liu, H.; Chen, B.; Niu, D.; Lei, B.; Ye, G.; Jiang, W.; Shi, Y.; Yin, L.; Lai, G. Amorphous Carbon-Induced Surface Defect Repair for Reinforcing the Mechanical Properties of Carbon Fiber. Materials 2019, 12, 1244. [CrossRef]

79. Pereira, A.L.C.; Schulz, P.A. Additional levels between Landau bands due to vacancies in graphene: Towards defect engineering. Phys. Rev. B 2008, 78, 125402. [CrossRef]

80. Li, M.; Deng, T.; Zheng, B.; Zhang, Y.; Liao, Y.; Zhou, H. Effect of Defects on the Mechanical and Thermal Properties of Graphene. Nanomaterials 2019, 9, 347. [CrossRef] [PubMed]

81. Panchakarla, L.S.; Subrahmanyam, K.S.; Saha, S.K.; Govindaraj, A.; Krishnamurthy, H.R.; Waghmare, U.V.; Rao, C.N.R. Synthesis, Structure, and Properties of Boron- and Nitrogen-Doped Graphene. Adv. Mater. 2009, 21, 4726-4730. [CrossRef]

82. Kim, Y.; Ryu, J.; Park, M.; Kim, E.S.; Yoo, J.M.; Park, J.; Kang, J.H.; Hong, B.H. Vapor-Phase Molecular Doping of Graphene for High-Performance Transparent Electrodes. ACS Nano 2013, 8, 868-874. [CrossRef] [PubMed]

83. Zhang, Y.; Wen, G.; Gao, P.; Bi, S.; Tang, X.; Wang, D. High-performance supercapacitor of macroscopic graphene hydrogels by partial reduction and nitrogen doping of graphene oxide. Electrochim. Acta 2016, 221, 167-176. [CrossRef]

84. Kc, S.; Longo, R.C.; Addou, R.; Wallace, R.; Cho, K. Impact of intrinsic atomic defects on the electronic structure of MoS2monolayers. Nanotechnology 2014, 25, 375703. [CrossRef]

85. Dang, K.; Spearot, D.E. Effect of point and grain boundary defects on the mechanical behavior of monolayer MoS2 under tension via atomistic simulations. J. Appl. Phys. 2014, 116, 013508. [CrossRef]

86. Park, J.-I.; Jang, Y.; Bae, J.-S.; Yoon, J.-H.; Lee, H.U.; Wakayama, Y.; Kim, J.-P.; Jeong, Y. Effect of thickness-dependent structural defects on electrical stability of MoS2 thin film transistors. J. Alloy. Compd. 2020, 814, 152134. [CrossRef]

87. Liu, D.; Guo, Y.; Fang, L.; Robertson, J. Sulfur vacancies in monolayer MoS2 and its electrical contacts. Appl. Phys. Lett. 2013, 103, 183113. [CrossRef]

88. Tedstone, A.A.; Lewis, D.J.; Hao, R.; Mao, S.-M.; Bellon, P.; Averback, R.S.; Warrens, C.P.; West, K.R.; Howard, P.; Gaemers, S.; et al. Mechanical Properties of Molybdenum Disulfide and the Effect of Doping: An In Situ TEM Study. ACS Appl. Mater. Interfaces 2015, 7, 20829-20834. [CrossRef] [PubMed]

89. Rai, A.; Valsaraj, A.; Movva, H.C.; Roy, A.; Ghosh, R.; Sonde, S.; Kang, S.; Chang, J.; Trivedi, T.; Dey, R.; et al. Air Stable Doping and Intrinsic Mobility Enhancement in Monolayer Molybdenum Disulfide by Amorphous Titanium Suboxide Encapsulation. Nano Lett. 2015, 15, 4329-4336. [CrossRef]

90. Ju, H.; Wang, R.; Ding, N.; Yu, L.; Xu, J.; Ahmed, F.; Zuo, B.; Geng, Y. Improvement on the oxidation resistance and tribological properties of molybdenum disulfide film by doping nitrogen. Mater. Des. 2020, 186, 108300. [CrossRef]

91. Tao, L.; Song, Y.; Liu, J.; Wang, X.; Liu, Z.; Huo, M.; Wang, Y.; Sui, Y. Tailoring physical properties of WS2 nanosheets by defects control. Nanotechnology 2020, 32, 035601. [CrossRef] [PubMed]

92. Chen, F.; Guo, H.; Zhao, L.; Zhu, Y.; Wang, X.; Chu, Y.; Li, S.; Guo, X. Defect Engineering can Enhance the Electrochemical Performance of WS2 for Thermal Batteries. J. Electrochem. Soc. 2021, 168, 103507. [CrossRef]

93. Wu, Z.; Luo, Z.; Shen, Y.; Zhao, W.; Wang, W.; Nan, H.; Guo, X.; Sun, L.; Wang, X.; You, Y.; et al. Defects as a factor limiting carrier mobility in WSe2: A spectroscopic investigation. Nano Res. 2016, 9, 3622-3631. [CrossRef]

94. Cui, Q.; Luo, Z.; Cui, Q.; Zhu, W.; Shou, H.; Wu, C.; Liu, Z.; Lin, Y.; Zhang, P.; Wei, S.; et al. Robust and High Photoluminescence in WS 2 Monolayer through In Situ Defect Engineering. Adv. Funct. Mater. 2021, 31, 2105339. [CrossRef]

95. Wang, W.; Bai, L.; Yang, C.; Fan, K.; Xie, Y.; Li, M. The Electronic Properties of O-Doped Pure and Sulfur Vacancy-Defect Monolayer WS2: A First-Principles Study. Materials 2018, 11, 218. [CrossRef] [PubMed]

96. Xu, S.; Gao, X.; Hu, M.; Sun, J.; Jiang, D.; Zhou, F.; Liu, W.; Weng, L. Nanostructured WS2-Ni composite films for improved oxidation, resistance and tribological performance. Appl. Surf. Sci. 2014, 288, 15-25. [CrossRef] 
97. Shen, Y.; Zheng, W.; Zhu, K.; Xiao, Y.; Wen, C.; Liu, Y.; Jing, X.; Lanza, M. Variability and Yield in h-BN-Based Memristive Circuits: The Role of Each Type of Defect. Adv. Mater. 2021, 33, 2103656. [CrossRef] [PubMed]

98. Li, J.-M. Robust 2D Room-Temperature Dilute Ferrimagnetism Enhancement in Freestanding Ammoniated Atom-Thin [0001] h-BN Nanoplates. ACS Appl. Mater. Interfaces 2017, 9, 39626-39634. [CrossRef]

99. Zhu, J.; Zhang, J.; Xu, S.; Hao, Y. Unintentional doping effects in black phosphorus by native vacancies in h-BN supporting layer. Appl. Surf. Sci. 2017, 402, 175-181. [CrossRef]

100. Rafiee, R.; Mahdavi, M. Molecular dynamics simulation of defected carbon nanotubes. Proc. Inst. Mech. Eng. Part L 2016, 230, 654-662. [CrossRef]

101. Ohnishi, M.; Shiga, T.; Shiomi, J. Effects of defects on thermoelectric properties of carbon nanotubes. Phys. Rev. B 2017, 95,155405 [CrossRef]

102. Kim, Y.; Kim, H. Structural modifications of multiwalled carbon nanotubes and their effects on optical properties. J. Nanopart. Res. 2014, 16, 1-11. [CrossRef]

103. Ionescu, M.I.; Zhang, Y.; Li, R.; Abou-Rachid, H.; Sun, X. Nitrogen-doping effects on the growth, structure and electrical performance of carbon nanotubes obtained by spray pyrolysis method. Appl. Surf. Sci. 2012, 258, 4563-4568. [CrossRef]

104. Ganesan, Y.; Peng, C.; Lu, Y.; Ci, L.; Srivastava, A.; Ajayan, P.M.; Lou, J. Effect of Nitrogen Doping on the Mechanical Properties of Carbon Nanotubes. ACS Nano 2010, 4, 7637-7643. [CrossRef] [PubMed]

105. Cui, T.; Lv, R.; Huang, Z.-H.; Kang, F.; Wang, K.; Wu, D. Effect of sulfur on enhancing nitrogen-doping and magnetic properties of carbon nanotubes. Nanoscale Res. Lett. 2011, 6, 77. [CrossRef] [PubMed]

106. Lim, S.H.; Elim, H.I.; Gao, X.Y.; Wee, A.; Ji, W.; Lee, J.Y.; Lin, J. Electronic and optical properties of nitrogen-doped multiwalled carbon nanotubes. Phys. Rev. B 2006, 73, 045402. [CrossRef]

107. Matsumura, K.; Takahashi, A.; Tsukamoto, J. Structure and electrical conductivity of graphite fibers prepared by pyrolysis of cyanoacetylene. Synth. Met. 1985, 11, 9-20. [CrossRef]

108. Kang, Z.; Johnson, R.; Mi, J.; Bondi, S.; Jiang, M.; Gillespie, J.; Lackey, W.; Stock, S.; More, K. Microstructure of carbon fibers prepared laser CVD. Carbon 2004, 42, 2721-2727. [CrossRef]

109. Varadan, V.K.; Hollinger, R.D.; Xie, J.; Sharma, P.K. Development and characterization of micro-coil carbon fibers by a microwave CVD system. Smart Mater. Struct. 2000, 9, 413-420. [CrossRef]

110. Feng, S.; Luo, W.; Wang, L.; Zhang, S.; Guo, N.; Xu, M.; Zhao, Z.; Jia, D.; Wang, X.; Jia, L. Preparation and property of extremely stable superhydrophobic carbon fibers with core-shell structure. Carbon 2019, 150, 284-291. [CrossRef]

111. Li, K.-Z.; Wang, C.; Li, H.-J.; Li, X.-T.; Ouyang, H.-B.; Wei, J. Effect of chemical vapor deposition treatment of carbon fibers on the reflectivity of carbon fiber-reinforced cement-based composites. Compos. Sci. Technol. 2008, 68, 1105-1114. [CrossRef]

112. Rong, H.; Dahmen, K.-H.; Garmestani, H.; Yu, M.; Jacob, K.I. Comparison of chemical vapor deposition and chemical grafting for improving the mechanical properties of carbon fiber/epoxy composites with multi-wall carbon nanotubes. J. Mater. Sci. 2013, 48, 4834-4842. [CrossRef]

113. Hu, Z.-H.; Dong, S.-M.; Hu, J.-B.; Wang, Z.; Lu, B.; Yang, J.-S.; Li, Q.-G.; Wu, B.; Gao, L.; Zhang, X.-Y. Synthesis of carbon nanotubes on carbon fibers by modified chemical vapor deposition. New Carbon Mater. 2012, 27, 352-361. [CrossRef]

114. Schedin, F.; Geim, A.K.; Morozov, S.; Hill, E.; Blake, P.; Katsnelson, M.I.; Novoselov, K. Detection of individual gas molecules adsorbed on graphene. Nat. Mater. 2007, 6, 652-655. [CrossRef] [PubMed]

115. Tanaka, S.; Morita, K.; Hibino, H. Anisotropic layer-by-layer growth of graphene on vicinal SiC(0001) surfaces. Phys. Rev. B 2010, 81, 041406. [CrossRef]

116. Juang, Z.-Y.; Wu, C.-Y.; Lu, A.-Y.; Su, C.Y.; Leou, K.-C.; Chen, F.-R.; Tsai, C.-H. Graphene synthesis by chemical vapor deposition and transfer by a roll-to-roll process. Carbon 2010, 48, 3169-3174. [CrossRef]

117. Machac, P.; Cichon, S.; Lapcak, L.; Fekete, L. Graphene prepared by chemical vapour deposition process. Graphene Technol. 2020, 5, 9-17. [CrossRef]

118. Lang, B. A LEED study of the deposition of carbon on platinum crystal surfaces. Surf. Sci. 1975, 53, 317-329. [CrossRef]

119. Eizenberg, M.; Blakely, J. Carbon monolayer phase condensation on Ni(111). Surf. Sci. 1979, 82, 228-236. [CrossRef]

120. Somani, P.R.; Somani, S.P.; Umeno, M. Planer nano-graphenes from camphor by CVD. Chem. Phys. Lett. 2006, 430, 56-59. [CrossRef]

121. Soriadi, N.; Abdullah, M.F.; Yakin, F.S.M.; Badaruddin, S.A.M.; Syono, M.I. Effect of Cu thickness and temperature on growth of graphene on 8-inch Cu/SiO2/Si wafer using cold-wall CVD reactor. Mater. Today 2021, 42, 2948-2952. [CrossRef]

122. Das, S.; Drucker, J. Nucleation and growth of single layer graphene on electrodeposited Cu by cold wall chemical vapor deposition. Nanotechnology 2017, 28, 105601. [CrossRef]

123. Jia, K.; Ci, H.; Zhang, J.; Sun, Z.; Ma, Z.; Zhu, Y.; Liu, S.; Liu, J.; Sun, L.; Liu, X.; et al. Superclean Growth of Graphene Using a Cold-Wall Chemical Vapor Deposition Approach. Angew. Chem. Int. Ed. 2020, 59, 17214-17218. [CrossRef] [PubMed]

124. Müller, F.; Stöwe, K.; Sachdev, H. Symmetry versus Commensurability: Epitaxial Growth of Hexagonal Boron Nitride on Pt(111) From B-Trichloroborazine (ClBNH). Chem. Mater. 2005, 17, 3464-3467. [CrossRef]

125. Lindvall, N.; Cole, M.T.; Yurgens, A. Large-area uniform graphene-like thin films grown by chemical vapor deposition directly on silicon nitride. Appl. Phys. Lett. 2011, 98, 252107. [CrossRef] 
126. Shi, Y.; Hamsen, C.; Jia, X.; Kim, K.K.; Reina, A.; Hofmann, M.; Hsu, A.L.; Zhang, K.; Li, H.; Juang, Z.-Y.; et al. Synthesis of Few-Layer Hexagonal Boron Nitride Thin Film by Chemical Vapor Deposition. Nano Lett. 2010, 10, 4134-4139. [CrossRef] [PubMed]

127. Qin, L.; Yu, J.; Li, M.; Liu, F.; Bai, X. Catalyst-free growth of mono- and few-atomic-layer boron nitride sheets by chemical vapor deposition. Nanotechnology 2011, 22, 215602. [CrossRef] [PubMed]

128. Lee, Y.-H.; Zhang, X.-Q.; Zhang, W.; Chang, M.-T.; Lin, C.-T.; Chang, K.-D.; Yu, Y.-C.; Wang, J.T.-W.; Chang, C.-S.; Li, L.-J.; et al. Synthesis of Large-Area MoS2Atomic Layers with Chemical Vapor Deposition. Adv. Mater. 2012, 24, 2320-2325. [CrossRef]

129. Alagh, A.; Annanouch, F.E.; Umek, P.; Bittencourt, C.; Sierra-Castillo, A.; Haye, E.; Colomer, J.F.; Llobet, E. CVD growth of self-assembled 2D and 1D WS2 nanomaterials for the ultrasensitive detection of NO2. Sens. Actuators B Chem. 2021, 326, 128813. [CrossRef]

130. Zhang, J.; Tahmasebi, A.; Omoriyekomwan, J.E.; Yu, J. Production of carbon nanotubes on bio-char at low temperature via microwave-assisted CVD using Ni catalyst. Diam. Relat. Mater. 2019, 91, 98-106. [CrossRef]

131. Shukrullah, S.; Naz, M.Y.; Mohamed, N.M.; Ibrahim, K.A.; Abdel-Salam, N.M.; Ghaffar, A. CVD Synthesis, Functionalization and CO2 Adsorption Attributes of Multiwalled Carbon Nanotubes. Processes 2019, 7, 634. [CrossRef]

132. Wang, J.; Liu, P.; Xia, B.; Wei, H.; Wei, Y.; Wu, Y.; Liu, K.; Zhang, L.; Wang, J.; Li, Q.; et al. Observation of Charge Generation and Transfer during CVD Growth of Carbon Nanotubes. Nano Lett. 2016, 16, 4102-4109. [CrossRef]

133. Li, P.; Zhang, J. CVD Growth of Carbon Nanotube Forest with Selective Wall-Number from Fe-Cu Catalyst. J. Phys. Chem. C 2016, 120, 11163-11169. [CrossRef]

134. Shah, K.A.; Najar, F.A.; Sharda, T.; Sreenivas, K. Synthesis of multi-walled carbon nanotubes by thermal CVD technique on Pt-W-MgO catalyst. J. Taibah Univ. Sci. 2018, 12, 230-234. [CrossRef]

135. Bandow, S.; Rao, A.M.; Williams, K.A.; Thess, A.; Smalley, A.R.E.; Eklund, P.C. Purification of Single-Wall Carbon Nanotubes by Microfiltration. J. Phys. Chem. B 1997, 101, 8839-8842. [CrossRef]

136. Colomer, J.-F.; Piedigrosso, P.; Fonseca, A.; Nagy, J. Different purification methods of carbon nanotubes produced by catalytic synthesis. Synth. Met. 1999, 103, 2482-2483. [CrossRef]

137. Bandow, S.; Asaka, S.; Zhao, X.; Ando, Y. Purification and magnetic properties of carbon nanotubes. Appl. Phys. A Mater. Sci. Process. 1998, 67, 23-27. [CrossRef]

138. Kim, Y.; Luzzi, D.E. Purification of Pulsed Laser Synthesized Single Wall Carbon Nanotubes by Magnetic Filtration. J. Phys. Chem. B 2005, 109, 16636-16643. [CrossRef] [PubMed]

139. Hou, P.; Liu, C.; Tong, Y.; Xu, S.; Liu, M.; Cheng, H. Purification of single-walled carbon nanotubes synthesized by the hydrogen arc-discharge method. J. Mater. Res. 2001, 16, 2526-2529. [CrossRef]

140. Nakahara, M.; Takada, T.; Kumagai, H.; Sanada, Y. Surface chemistry of carbon black through curing process of epoxy resin. Carbon 1995, 33, 1537-1540. [CrossRef]

141. Tsang, S.C.; Harris, P.J.F.; Green, M.L.H. Thinning and opening of carbon nanotubes by oxidation using carbon dioxide. Nature 1993, 362, 520-522. [CrossRef]

142. Ajayan, P.M.; Ebbesen, T.W.; Ichihashi, T.; Iijima, S.; Tanigaki, K.; Hiura, H. Opening carbon nanotubes with oxygen and implications for filling. Nat. Cell Biol. 1993, 362, 522-525. [CrossRef]

143. Chen, Y.K.; Green, M.L.H.; Griffin, J.L.; Hammer, J.; Lago, R.M.; Tsang, S.C. Purification and opening of carbon nanotubes via bromination. Adv. Mater. 1996, 8, 1012-1015. [CrossRef]

144. Dillon, A.C.; Gennett, T.; Jones, K.M.; Alleman, J.L.; Parilla, P.A.; Heben, M.J. A simple and complete purification of single-walled carbon nanotube materials. Adv. Mater. 1999, 11, 1354-1358. [CrossRef]

145. Hou, P.; Bai, S.; Yang, Q.; Liu, C.; Cheng, H.-M. Multi-step purification of carbon nanotubes. Carbon 2002, 40, 81-85. [CrossRef]

146. Strong, K.L.; Anderson, D.P.; Lafdi, K.; Kuhn, J.N. Purification process for single-wall carbon nanotubes. Carbon 2003, 41, 1477-1488. [CrossRef]

147. Lambert, J.; Ajayan, P.; Bernier, P.; Planeix, J.; Brotons, V.; Coq, B.; Castaing, J. Improving conditions towards isolating single-shell carbon nanotubes. Chem. Phys. Lett. 1994, 226, 364-371. [CrossRef]

148. Li, F.; Cheng, H.; Xing, Y.; Tan, P.-H.; Su, G. Purification of single-walled carbon nanotubes synthesized by the catalytic decomposition of hydrocarbons. Carbon 2000, 38, 2041-2045. [CrossRef]

149. Chattopadhyay, D.; Galeska, I.; Papadimitrakopoulos, F. Complete elimination of metal catalysts from single wall carbon nanotubes. Carbon 2002, 40, 985-988. [CrossRef]

150. Ebbesen, T.W. Carbon Nanotubes: Preparation and Properties; CRC Press: Boca Raton, FL, USA, 1997 ; Volume 225.

151. Andrews, R.; Jacques, D.; Qian, D.; Dickey, E. Purification and structural annealing of multiwalled carbon nanotubes at graphitization temperatures. Carbon 2001, 39, 1681-1687. [CrossRef]

152. Chen, X.; Chen, C.; Chen, Q.; Cheng, F.; Zhang, G.; Chen, Z. Non-destructive purification of multi-walled carbon nanotubes produced by catalyzed CVD. Mater. Lett. 2002, 57,734-738. [CrossRef]

153. Biró, L.; Khanh, N.; Vértesy, Z.; Horváth, Z.; Osváth, Z.; Koós, A.; Gyulai, J.; Kocsonya, A.; Kónya, Z.; Zhang, X.; et al. Catalyst traces and other impurities in chemically purified carbon nanotubes grown by CVD. Mater. Sci. Eng. C Mater. Biol. Appl. 2002, 19, 9-13. [CrossRef]

154. Yousef, S.; Mohamed, A. Mass production of CNTs using CVD multi-quartz tubes. J. Mech. Sci. Technol. 2016, 30, 5135-5141. [CrossRef] 
155. Shandakov, S.; Kosobutsky, A.; Rybakov, M.S.; Sevostyanov, O.G.; Russakov, D.; Lomakin, M.; Bershinina, A.; Chirkova, I.M. Effect of gaseous and condensate products of ethanol decomposition on aerosol CVD synthesis of single-walled carbon nanotubes. Carbon 2018, 126, 522-531. [CrossRef]

156. Tripathi, P.K.; Durbach, S.; Coville, N.J. Synthesis of Multi-Walled Carbon Nanotubes from Plastic Waste Using a Stainless-Steel CVD Reactor as Catalyst. Nanomaterials 2017, 7, 284. [CrossRef] [PubMed]

157. Eveleens, C.A.; Irle, S.; Page, A.J. How does acetonitrile modulate single-walled carbon nanotube diameter during CVD growth? Carbon 2019, 146, 535-541. [CrossRef]

158. Li, Q.; Yan, H.; Zhang, J.; Liu, Z. Effect of hydrocarbons precursors on the formation of carbon nanotubes in chemical vapor deposition. Carbon 2004, 42, 829-835. [CrossRef]

159. Shukrullah, S.; Mohamed, N.M.; Shaharun, M.S.; Naz, M.Y. Effect of Ethylene Flow Rate and CVD Process Time on Diameter Distribution of MWCNTs. Mater. Manuf. Process. 2016, 31, 1537-1542. [CrossRef]

160. Basheer, H.J.; Pachot, C.; Lafont, U.; Devaux, X.; Bahlawane, N. Low-Temperature Thermal CVD of Superblack Carbon Nanotube Coatings. Adv. Mater. Interfaces 2017, 4, 1700238. [CrossRef]

161. Diao, G.; Li, H.; Liang, H.; Ivanenko, I.; Dontsova, T.; Astrelin, I. CVD Synthesis of Multi-Walled Carbon Nanotubes onto Different Catalysts at Low Temperature. Nano 2018, 13, 1850036. [CrossRef]

162. Qingwen, L.; Hao, Y.; Yan, C.; Jin, Z.; Zhongfan, L. A scalable CVD synthesis of high-purity single-walled carbon nanotubes with porous $\mathrm{MgO}$ as support material. J. Mater. Chem. 2002, 12, 1179-1183. [CrossRef]

163. Zheng, G.-B.; Kouda, K.; Sano, H.; Uchiyama, Y.; Shi, Y.-F.; Quan, H.-J. A model for the structure and growth of carbon nanofibers synthesized by the CVD method using nickel as a catalyst. Carbon 2004, 42, 635-640. [CrossRef]

164. Chen, C.; Zhang, Z.-Y.; Revilla, R.I.; Zhao, W.; Pourkazemi, A.; Hauffman, T.; Yan, J.; Peng, Y.; Stiens, J. Mechanism of the Polarized Absorption of CVD-Prepared Carbon Nanofibers to TE Waves in the Subterahertz Band. J. Phys. Chem. C 2020, 124, 24957-24969. [CrossRef]

165. Ting, J.-M.; Huang, N. Thickening of chemical vapor deposited carbon fiber. Carbon 2001, 39, 835-839. [CrossRef]

166. Xue, Y.; Wu, B.; Guo, Y.; Huang, L.; Jiang, L.; Chen, J.; Geng, D.; Liu, Y.; Hu, W.; Yu, G. Synthesis of large-area, few-layer graphene on iron foil by chemical vapor deposition. Nano Res. 2011, 4, 1208-1214. [CrossRef]

167. Kim, E.; An, H.; Jang, H.; Cho, W.-J.; Lee, N.; Lee, W.-G.; Jung, J. Growth of Few-Layer Graphene on a Thin Cobalt Film on a $\mathrm{Si} / \mathrm{SiO} 2$ Substrate. Chem. Vap. Depos. 2011, 17, 9-14. [CrossRef]

168. Van Nang, L.; Kim, E.-T. Low-temperature synthesis of graphene on Fe2O3 using inductively coupled plasma chemical vapor deposition. Mater. Lett. 2013, 92, 437-439. [CrossRef]

169. Kleijn, C.; Dorsman, R.; Kuijlaars, K.; Okkerse, M.; van Santen, H. Multi-scale modeling of chemical vapor deposition processes for thin film technology. J. Cryst. Growth 2007, 303, 362-380. [CrossRef]

170. Mishra, P.; Verma, N. A CFD study on a vertical chemical vapor deposition reactor for growing carbon nanofibers. Chem. Eng. Res. Des. 2012, 90, 2293-2301. [CrossRef]

171. Huet, B.; Zhang, X.; Redwing, J.M.; Snyder, D.W.; Raskin, J.-P. Multi-wafer batch synthesis of graphene on Cu films by quasi-static flow chemical vapor deposition. 2D Mater. 2019, 6, 045032. [CrossRef]

172. He, S.-M.; Lin, Z.-L.; Lin, W.-J.; Xu, K.-X.; Chen, Y.-H.; Chen, J.-C.; Su, C.-Y. Toward large-scale CVD graphene growth by enhancing reaction kinetics via an efficient interdiffusion mediator and mechanism study utilizing CFD simulations. J. Taiwan Inst. Chem. Eng. 2021, 128, 400-408. [CrossRef]

173. Fauzi, F.B.; Ismail, E.; Osman, M.N.; Rosli, M.S.; Ismail, A.F.; Mohamed, M.A.; Abu Bakar, S.N.S.; Ani, M.H. Influence of mixed convection in atmospheric pressure chemical vapor deposition of graphene growth. Mater. Today Proc. 2019, 7, 638-645. [CrossRef]

174. Gao, W.; Zhou, G.; Li, J.; Chen, T.; Li, B.; Xiao, X.; Li, Y.; Huang, K.; Xiao, S.; Hao, G. Controllable epitaxial growth of GeSe2 nanostructures and nonlinear optical properties. Nanotechnology 2021, 32, 465704. [CrossRef]

175. Zhou, D.; Lang, J.; Yoo, N.; Unocic, R.R.; Wu, Q.; Li, B. Fluid-Guided CVD Growth for Large-Scale Monolayer Two-Dimensional Materials. ACS Appl. Mater. Interfaces 2020, 12, 26342-26349. [CrossRef]

176. Kim, M.; Lee, Y.H.; Oh, J.-H.; Hong, S.-H.; Min, B.-I.; Kim, T.-H.; Choi, S. Synthesis of boron nitride nanotubes using triple DC thermal plasma reactor with hydrogen injection. Chem. Eng. J. 2020, 395, 125148. [CrossRef]

177. Yao, W.; Sun, J.; Chen, J.; Wu, B.; Liu, Y. Controllable synthesis of graphene by CVD method. Chin. Sci. Bull. 2020, 65, 3134-3149. [CrossRef]

178. Stinespring, C.; Wormhoudt, J. Gas phase kinetics analysis and implications for silicon carbide chemical vapor deposition. J. Cryst. Growth 1988, 87, 481-493. [CrossRef]

179. Gokoglu, S.A.; Kuczmarski, M.; Tsui, P.; Chait, A. Convection and Chemistry Effects in Cvd-A 3-D Analysis for Silicon Deposition. J. Phys. Colloq. 1989, 50, 17-34. [CrossRef]

180. De Jong, F.; Meyyappan, M. Numerical simulation of silicon carbide chemical vapor deposition. Diam. Relat. Mater. 1996, 5, 141-150. [CrossRef]

181. Kleijn, C.R. Computational modeling of transport phenomena and detailed chemistry in chemical vapor deposition-A benchmark solution. Thin Solid Films 2000, 365, 294-306. [CrossRef]

182. Vorob'Ev, A.; Karpov, S.; Bord, O.; Zhmakin, A.; Lovtsus, A.; Makarov, Y. Modeling of gas phase nucleation during silicon carbide chemical vapor deposition. Diam. Relat. Mater. 2000, 9, 472-475. [CrossRef] 
183. Mazumder, S.; Lowry, S.A. The importance of predicting rate-limited growth for accurate modeling of commercial MOCVD reactors. J. Cryst. Growth 2001, 224, 165-174. [CrossRef]

184. Kremer, D.; Davis, R.; Moore, E.; Ehrman, S. A numerical investigation of the effects of gas-phase particle formation on silicon film deposition from silane. J. Cryst. Growth 2003, 247, 333-356. [CrossRef]

185. Im, I.-T.; Oh, H.J.; Sugiyama, M.; Nakano, Y.; Shimogaki, Y. Fundamental kinetics determining growth rate profiles of InP and GaAs in MOCVD with horizontal reactor. J. Cryst. Growth 2004, 261, 214-224. [CrossRef]

186. Danielsson, Ö.; Henry, A.; Janzén, E. Growth rate predictions of chemical vapor deposited silicon carbide epitaxial layers. J. Cryst. Growth 2002, 243, 170-184. [CrossRef]

187. Endo, H.; Kuwana, K.; Saito, K.; Qian, D.; Andrews, R.; Grulke, E.A. CFD prediction of carbon nanotube production rate in a CVD reactor. Chem. Phys. Lett. 2004, 387, 307-311. [CrossRef]

188. Moraveji, M.K.; Sokout, F.S.; Rashidi, A. CFD modeling and experimental study of multi-walled carbon nanotubes production by fluidized bed catalytic chemical vapor deposition. Int. Commun. Heat Mass Transf. 2011, 38, 984-989. [CrossRef]

189. Seo, J.-W.; Kim, J.-W.; Choi, K.; Lee, J.-H. Improvement of uniformity in chemical vapor deposition of silicon carbide by using CFD. J. Korean Phys. Soc. 2016, 68, 170-175. [CrossRef]

190. Xu, B.; Kaneko, T.; Kato, T. Improvement in growth yield of single-walled carbon nanotubes with narrow chirality distribution by pulse plasma CVD. Front. Chem. Sci. Eng. 2019, 13, 485-492. [CrossRef]

191. Kleijn, C.; Hoogendoorn, C. A study of 2- and 3-D transport phenomena in horizontal chemical vapor deposition reactors. Chem. Eng. Sci. 1991, 46, 321-334. [CrossRef]

192. Kim, Y.-J.; Boo, J.-H.; Hong, B.; Kim, Y.J. Effects of showerhead shapes on the flowfields in a RF-PECVD reactor. Surf. Coat. Technol. 2005, 193, 88-93. [CrossRef]

193. Min, W.; Jiang, W. Numerical simulation of the effect of nozzle type chemical vapor deposition reactor structure on the growth of carbon nanotubes. J. Nanchang Aviat. Univ. Nat. Sci. Ed. 2014, 28, 46-50. (In Chinese) [CrossRef]

194. Zhao, J.; Liu, L.; Guo, Q.; Shi, J.; Zhai, G. Multi-physical simulation of CVD process for growth of carbon nanotubes. J. Mater. Eng. 2007, 1, 11-14. (In Chinese) [CrossRef]

195. Xu, Z.; Wu, L.; Chen, T. Research progress of direct-spinning based fabrication of carbon nanotube fibers. China Text. Lead. 2019, 6, 67-71. (In Chinese) [CrossRef]

196. Kleijn, C. On the modelling of transport phenomena in chemical vapour deposition and its use in reactor design and process optimization. Thin Solid Films 1991, 206, 47-53. [CrossRef]

197. Minakov, A.V.; Simunin, M.M.; Ryzhkov, I.I. Modelling of ethanol pyrolysis in a commercial CVD reactor for growing carbon layers on alumina substrates. Int. J. Heat Mass Transf. 2019, 145, 118764. [CrossRef]

198. Tian, H.; Hao, B.; Xun, J.; Tian, Y.; Wen, H. Research progress of experimental and simulation study on ZnO nano/microstructures by chemical vapor deposition. Mater. Rev. 2016, 30, 33-40. (In Chinese) [CrossRef]

199. Deng, W.; Huang, Y. Optimization of Substrate Temperature for Uniform Graphene Synthesis by Numerical Simulation and Machine Learning. Cryst. Res. Technol. 2021, 56, 2100006. [CrossRef]

200. Xu, J.; Hu, J.; Li, Q.; Wang, R.; Li, W.; Guo, Y.; Zhu, Y.; Liu, F.; Ullah, Z.; Dong, G.; et al. Fast Batch Production of High-Quality Graphene Films in a Sealed Thermal Molecular Movement System. Small 2017, 13, 1700651. [CrossRef]

201. Guo, X.Q. The performance and application of carbon nanotubes. Carbon 2018, 2, 40-46. (In Chinese) [CrossRef]

202. Yue, L.; Zhang, S.; Zhao, H.; Feng, Y.; Wang, M.; An, L.; Zhang, X.; Mi, J. One-pot synthesis CoFe2O4/CNTs composite for asymmetric supercapacitor electrode. Solid State Ionics 2019, 329, 15-24. [CrossRef] 